\title{
Das Kunstwerk trauert - das Kunstwerk feiert. Grabmal und Denkmal Ludwig Anzengrubers in Wien im europäischen Kontext
}

\author{
Hans KÖRNER
}

\begin{abstract}
„Sweat must freely flow“ and without the „blessing ... from higher" it is not possible anyway, but if both are given, the work praises the master. The poetic phrase from Schiller's "Song of the Bell" could be made visible in the art of monuments and tombs. Works of art praise their creator in a monument, works of art mourn for their creator in a tomb. They belong to the staff of the accompanying figures at the memorial / grave, together with personifications, geniuses and muses. The essay tells the story of this visualization. It focuses on two monuments in Vienna: Ludwig Anzengruber's grave of honour in the Vienna Central Cemetery (1893) and the Anzengruber monument on Schmerlingplatz, Vienna (1905) - both works by Hans Scherpe. The relationship between the work of art and the mourned / honoured artist is discussed and placed in the European context.
\end{abstract}

Keywords: Anzengruber, tomb, monument, Vienna

Schweiß muss rinnen und ohne den göttlichen Segen geht es ohnedies nicht, doch wenn beides gegeben ist, lobt das Werk den Meister. Die poetische Wendung aus Schillers „Lied von der Glocke“ konnte in der Denkmals- und Grabmalskunst sichtbar gemacht werden. Kunstwerke rühmen im Denkmal ihren Schöpfer, Kunstwerke trauern im Grabmal um ihren Schöpfer. Sie gehören zum Personal der Beifiguren am Denkmal/Grabmal, gemeinsam mit Personifikationen, Genien, Musen, allgemeinen und individualisierten Trauerfiguren. Die Geschichte dieser Verbildlichung soll im folgenden erzählt werden. Perspektive und Mittelpunkt werden zwei Denkmäler in Wien sein - ein Grabdenkmal auf dem Zentralfriedhof und ein Denkmal auf dem Schmerlingplatz. Beide stammen in der Konzeption und im Figürlichen von Hans Scherpe und beide sind Ludwig Anzengruber gewidmet.

\section{Von den Allegorien der Künste am Grabmal zu Pierre Mignards trauernder Tochter}

Michelangelo hatte sich mit der Absicht getragen, eine Pietà von seiner Hand - die heute im Florentiner Dommuseum gezeigte, vormals im Florentiner Dom aufgestellte Beweinungsgruppe - dem eigenen Grabmal als Grabbild beizugeben. Unglücklich über den Fortschritt der Arbeit beschädigte Michelangelo 1555 sein Werk und gab es erst an einen Bediensteten weiter, bevor er es einem Bankier schenkte. ${ }^{1}$ Nach dem Tod Michelangelos kam auch der „Sieger“ für die Funktion als Grabbild ins Gespräch. Beides wur-

\footnotetext{
SCHÜTZ-RAUTENBERG, G.: Künstlergrabmäler des 15. und 16. Jahrhunderts in Italien. Ein Beitrag zur Sozialgeschichte der Künstler. Köln - Wien 1978, S. 149 ff.
} 


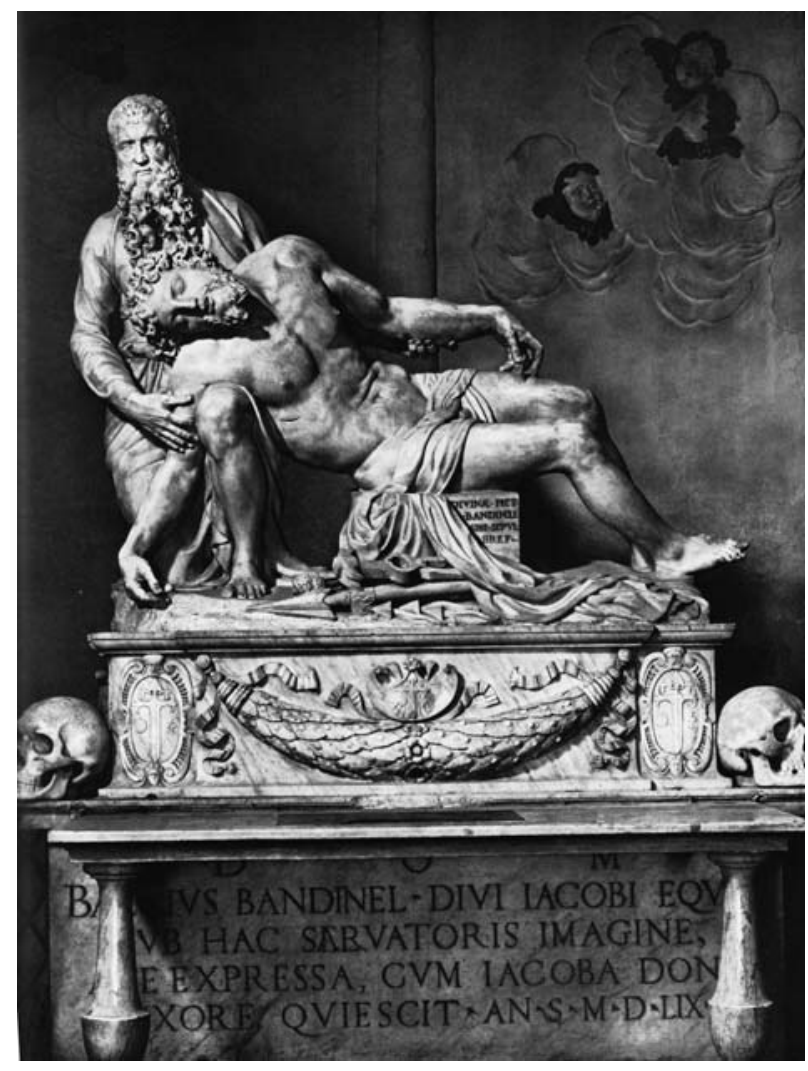

Abb. 1: Bandinelli, Baccio, Grablegung Christi, 1554-59, Florenz, SS. Annunziata (Bildzitat aus: Kauffmann, Georg, Die Kunst des 16. Jabrhunderts. Propyläen Kunstgeschichte, Bd. 8., Berlin 1970, Taf. 203)

de abgewiesen, weil Vasari darauf insistiert hatte, Cosimo I. de' Medici die im Atelier verbliebenen Werke zu überlassen, vielleicht auch, weil die Akademie sich mit der Ehrung für Michelangelo in S. Croce selbst ein Denkmal setzen wollte. ${ }^{2}$ Baccio Bandinelli griff die Idee des Rivalen auf. ${ }^{3}$ Der rechte Seitenaltar in SS. Annunziata in Florenz verweist auf die Grablege des

\footnotetext{
KUSCH-ARNHOLD, B.: Solcher Tugend gebührte nicht weniger! Die Exequien Michelangelo Buonarottis und das Grabmal des Künstlers. In: Praemium V irtutis II. : Grabmäler und Begräbniszeremoniell in der italienischen Renaissance. Ed.: POESCHKE, J. - KUSCH-ARNHOLD, B. - WEIGEL, T. Münster 2005, S. 86 ff.

3 Hierzu und zum folgenden: SCHÜTZ-RAUTENBERG 1978 (wie Anm. 1), S. 162 ff.
}

Künstlers (die ihm allerdings nur mit gehöriger Distanz zum Altar zugestanden wurde), markiert aber auch die Lebensleistung des Verstorbenen durch ein/ sein Kunstwerk. (Abb. 1) Wie der Evangelist Lukas als legendärer erster „Porträtist“ der Muttergottes zum Patron der Maler aufstieg, wurde Nikodemus zum biblischen Schirmherrn der Bildhauer. Der von Nikodemus/Bandinelli getragene/geschaffene tote Christus bezieht den Tod des Künstlers Bandinelli thematisch auf das Erlösungswerk der Passion und bezieht sich als Kunstwerk auf den Künstler Bandinelli.

An Michelangelos Grabmal in S. Croce, Florenz (vorher bereits an seinem Katafalk) erscheinen erstmals Personifikationen der Künste, um einen Künstler zu ehren. ${ }^{4}$ (Abb. 2) Probleme gab es hinsichtlich der Aufstellung: Zunächst war geplant, der Personifikation der Malerei den mittleren, damit hervorgehobenen Platz zu geben. Der Protest des Grabmalsstifters Lionardo, der darauf verwies, dass Michelangelo sich vorzüglich als Bildhauer verstanden habe, verschaffte im ausgeführten Grabmal der „scultura“ den zentralen Platz unter den Künsten. Doch weil die gemäß dem ursprünglichen Konzept bereits weitgehend fertiggestellte „scultura“ ihrer Körperwendung wegen und deshalb in Hinblick auf die Gesamtwirkung für eine Aufstellung links am Sockel besser geeignet schien, mussten einige wenige Änderungen hinreichen, um aus ihr eine „pittura“ zu machen. ${ }^{5}$ Überbleibsel der vormaligen Ikonographie ist der Bozzetto eines männlichen Aktes, den nun - nicht mehr recht passend - die „pittura“ mit der rechten Hand hält. Die Statuette ähnelt zumindest dem „Jugendlichen Sklaven“ der „Accademia“. 6 So erscheint mit dem ersten Auftreten von Personifikationen der Künste am Künstlergrabmal auch erstmals ein Kunstwerk des Verstorbenen am Grabmal, das nicht nur implizit als Kunstwerk

4 BONNET, A.: Le peintre statufié. In: Revue de l'art, 162, 2008, S. 21-31, hier S. 24, WINKLER, E.: Die Personifikationen der drei bildenden Künste. Funktionalisierungen eines frübneuzeitlichen Bildpersonals ( $=$ Ars et Scientia. Schriften zur Kunstwissenschaft, Bd. 20), Berlin - Boston 2018, S. 237 ff.

5 WINKLER 2018 (wie Anm. 4), S. 256 f.

${ }^{6}$ Ibidem, S. 258. 
des Verstorbenen fungierte, wie es Michelangelo mit seiner Pietà geplant und Baccio Bandinelli verwirklicht hatten, sondern explizit. Allerdings ist in diesem Kontext die Statuette nur ein Attribut. Um selbst aktiv Trauerarbeit betreiben zu können, musste das Attribut selbst zur Allegorie aufsteigen und die Allegorie wiederum so konkret und so aktiv werden, dass der Zeichencharakter des Allegorischen zwar nicht aufgehoben, aber beiläufig wird.

Gianlorenzo Bernini hatte an den Grabmälern für Papst Urban VIII. und für Alexander VII. in St. Peter die Tugendallegorien soweit, geerdet', dass die allegorische Botschaft mit einer allgemein menschlichen Trauerhaltung zusammenfällt. Der nächste Schritt bestand darin, solche aus der Abstraktion herausgeholten und in ihrer Trauer aktivierten Allegorien zu individualisieren. Diesen Schritt ging die französische Grabmalskunst seit dem 17. Jh. 1691 war François Michel Le Tellier de Louvois, der Kriegsminister Ludwigs XIV., kurz nach einer Unterredung mit dem König plötzlich verstorben. Seine Gattin, Anne de Souvré, ließ ihm ein aufwendiges Grabmal im Invalidendom errichten, das allerdings bereits 1699 in die bescheidenere Kapuzinerkirche versetzt wurde. In den Jahren der Revolution entsorgte man die sterblichen Überreste des Ministers; verschont und deponiert im Musée des Augustins blieben das Grabbild des Verstorbenen, die neben dem Verstorbenen sitzende Gattin, sowie zwei bronzene Allegorien. Während der Restauration veranlassten die Nachkommen die Neuaufstellung des Monuments im Hôtel Dieu von Tonnerre. ${ }^{7}$ (Abb. 3) Auf dem Sarkophag liegt der Verstorbene mit aufgerichtetem Oberkörper, eine im französischen 17. und 18. Jh. übliche Darstellungsform, die auf die christliche Auferstehungshoffnung verweist, fromme Hinwendung ist. Prominent vertritt diesen Typus das Grabmal für Kardinal Richelieu - ebenfalls ein Werk von François Girardon - in der Kirche der Sorbonne. Richelieu hatte gewünscht, ,en action de s'offrir à Dieu“ dargestellt zu sein. ${ }^{8}$ Girardon, der erst 1675 mit der Arbeit am Grabmal begann, kam diesem im Auftrag festgehaltenen Wunsch des Verstorbenen

\footnotetext{
https://hoteldieudetonnerre.jimdo.com/le-marquis-de-louvois/ (15. 11. 2019). https:/ /www.landrucimetieres.fr/spip/ spip.php?article1669 (15.11.2019)
}

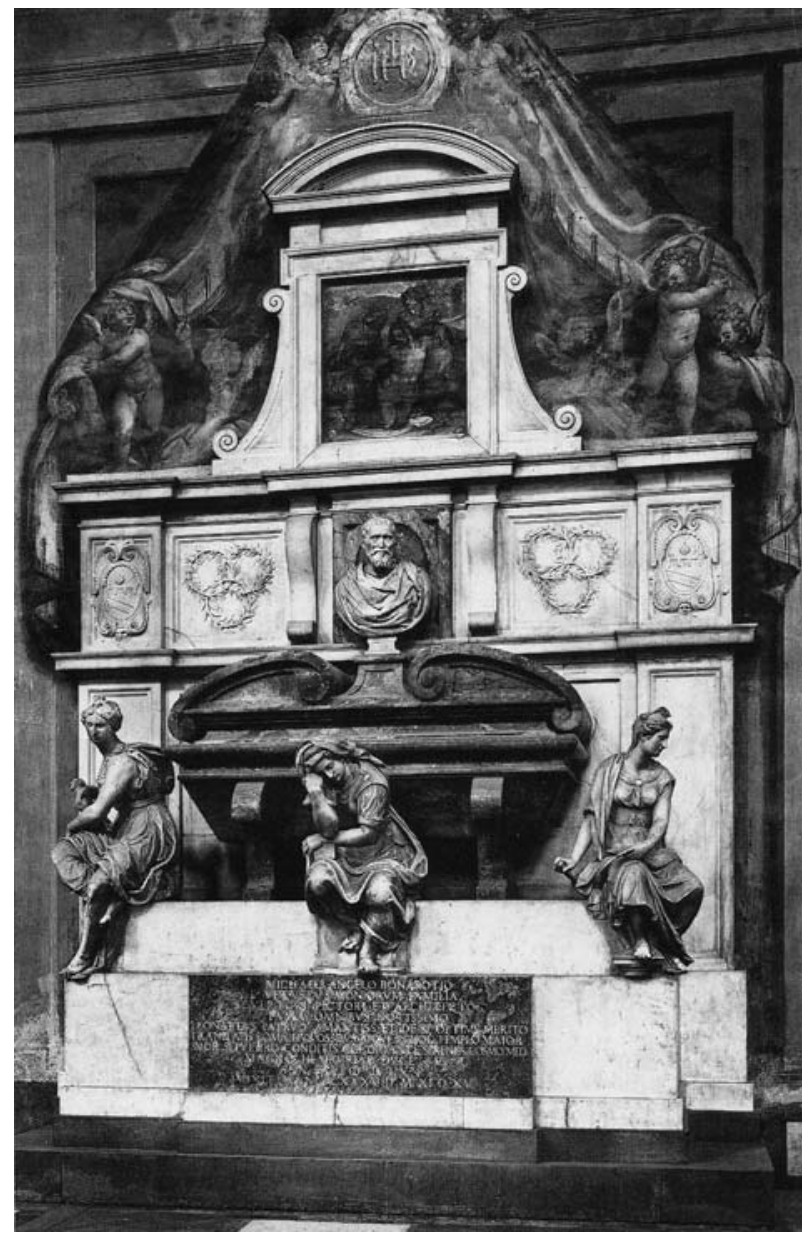

Abb. 2: Vasari, Giorgio / Borghini, Vincenzo (Entwurf), Lorenzi del Cavaliere, Battista di Domenico / Cioli, Valerio / Bandini, Giovanni / Naldini, Giambattista, Grabmal Michelangelos, 1564-78, Florenæ, S. Croce (Bildzitat aus: Poeschke, Joachim, Die Skulptur der Renaissance in Italien. Band 2: Michelangelo und seine Zeit, München 1992, Abb. 3)

nach: Richelieu richtet sich auf, blickt nach oben und führt andächtig die Rechte vor die Brust. Zwei Allegorien sind ihm beigegeben: die Verkörperung der „Doctrina“, die in Trauer zu Füßen des Kardinals zusammengesunken ist, sowie die Personifikation der „Pietas“, die Richelieus Oberkörper von hinten stützt, ihn liebevoll anblickt und ein Buch präsen-

8 PETZET, M.: Französische Plastik. In: HUBALA, E.: Die Kunst des 17. Jabrbunderts (= Propyläen Kunstgeschichte Bd. 9), Berlin 1970, S. 257-260, hier S. 259. 


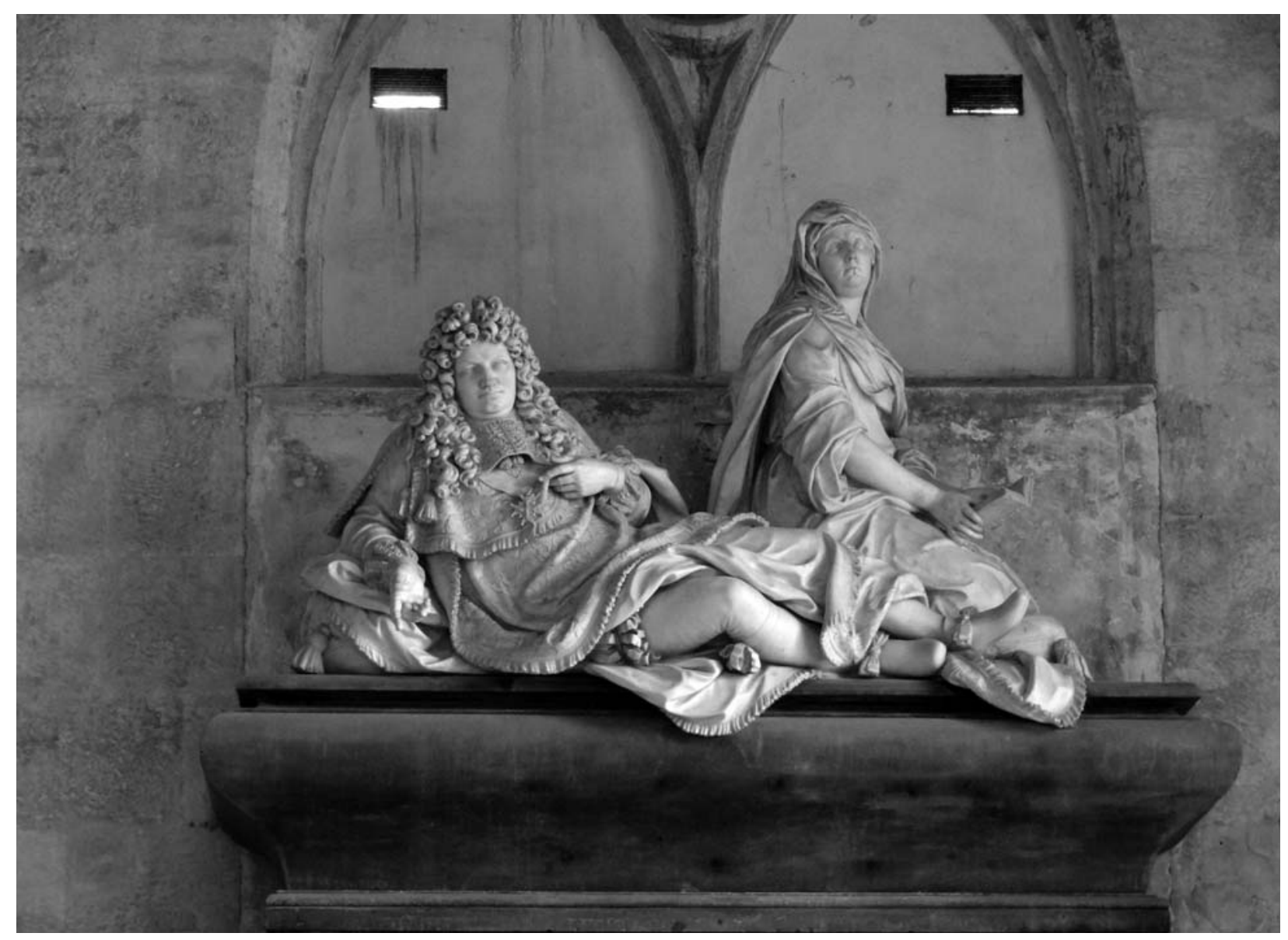

Abb. 3: Girardon, François u. a., Grabmal von François Michel Le Tellier de Lowvois (+ 1691), Tonnerre, Hôtel Dieu (Wikimedia Commons. Foto: FLLL)

tiert. ${ }^{9}$ Offensichtlich sind die „Pietas“ im Grabmal der Sorbonne-Kirche und die Gattin Michel Le Telliers mit dem Gebetbuch in der Hand motivisch analog. In Tonnerre ist die Allegorie der Frömmigkeit individualisiert. An die Stelle der Allegorie tritt, besser: mit der Allegorie verschmilzt die Gattin des Toten, Anne de Souvré.

In die Nachfolge dieser Lösung stellte sich die Auftraggeberin des Grabmals für den Maler Pierre

\footnotetext{
9 Ibidem, S. 259.

${ }^{10}$ Hierzu, zur Beziehung dieses Grabmals zu Coyevox' Grabmal für Mignards Konkurrenten Charles Le Brun und zur Beziehung beider zum Grabmal für Michelangelo in S. Croce, Florenz: HAUSDORF, E.: „Un tombeau qui devoit leur être
}

Mignard. Den Verstorbenem repräsentiert eine Büste, einmal mehr ein Werk François Girardons, aber geschaffen noch ohne Grabmalsbezug. Mignards Tochter Cathérine hatte 1697 mit dem Bildhauer Jean Dedieu einen Vertrag über ein Grabmal geschlossen, in das die Büste integriert sein und in dem eine Allegorie der Malerei den Toten betrauern sollte. ${ }^{10}$ Erst 1735 begann Jean-Baptiste Lemoyne mit der Ausführung, mit bemerkenswerten Veränderungen

commun“. Das Grabmal für Pierre Mignard (1735-1744) im Wandel vom Künstlergrab zum Monument der Tochterliebe. In: Künstlergrabmäler. Genese - Typologie - Intention - Metamorphose. Eds.: MÜNCH, B. U. - HERZOG, M. - TACKE, A. Petersberg 2011, S. 166-184, hier S. 171 f. 
gegenüber dem vertraglich mit Dedieu vereinbarten Konzept. ${ }^{11}$ (Abb. 4) Beibehalten ist Girardons Büste, von der Chronos theatralisch den Vorhang wegzog. Die Profession Mignards bezeichneten Palette und Pinsel zu Füßen des weinenden Putto, der vor der weitgehenden Zerstörung des Monuments während der Revolution den Toten beklagte. Die entscheidende Veränderung betraf die weibliche Trauerfigur. Anstelle einer Allegorie der Malerei betet und trauert jetzt die Tochter Cathérine vor der Büste des Vaters.

Die Änderung erfolgte auch in Hinblick auf die von der Auftraggeberin gewünschte gemeinsame Bestattung mit dem Vater, meint aber zunächst eine Individualisierung und Konkretisierung des allegorisch Allgemeinen. Dieses Allgemeine war im Porträt Cathérine Mignards präsent gehalten durch die Beigabe der Werkzeuge der Malerei, und gleichzeitig konkretisierte sich dieses Allgemeine (die von der Tochter mitverkörperte Allegorie der Malerei) möglicherweise wiederum in einem Kunstwerk, hier besser: einer Werkreihe Mignards. Darauf deutet ein von Eva Hausdorf unterstrichener motivgeschichtlicher Zusammenhang: Die Pose der trauernden Tochter ähnelt dem Typus der unter dem Kreuz trauernden Maria Magdalena, und folgerichtig ordnete man die Trauernde, als die Reste des im Musée des Monuments français aufbewahrten Grabmals wieder zurück in einen Sakrakraum (Saint-Roch) versetzt wurden, zunächst nicht der Mignard-Büste Girardons, sondern der Kreuzigungsdarstellung im Chor zu: als den Gekreuzigten betrauernde Magdalena. ${ }^{12}$ Auf dem Weg über die motivgeschichtliche Analogie stellte sich ein Zusammenhang her, der auf Pierre Mignard als Künstler zurückverwies: Neben anderem hatte Mignard sich Ruhm durch seine Hofdamenporträts ,à la Madeleine“ erworben. ${ }^{13}$

Cathérine Mignard ist kein zum lebenden Bild gewordenes (und wieder versteinertes) Bildnis ,à la Madeleine" Pierre Mignards; sie spielt nur darauf an. Das 19. Jh. wird die Individualisierung von Trauerfiguren am Grabmal zu einem zentralen Thema der

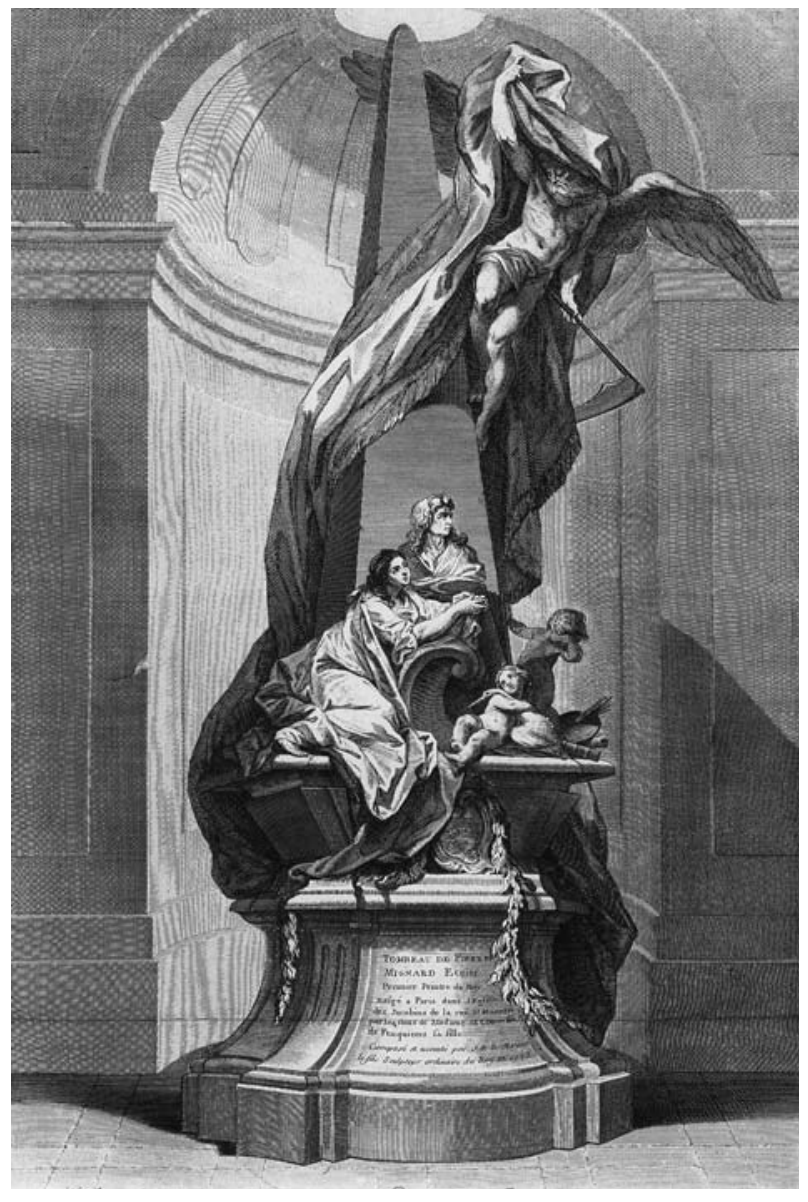

Abb. 4: Lépicié, Nicolas Bernard, Stich nach: Lemoyne, Jean-Baptiste, Grabmal für Pierre Mignard (Büstenporträt: Francois Giradon), 1735 44, ehem. Paris, Église des Jacobins, 1743, Paris, Bibliothèque Nationale (Bildritat aus: Levey, Michael, Painting and Sculpture in France 17001789 (1972), Yale 1993, Abb. 94)

Sepulkralkunst machen, ${ }^{14}$ und bevorzugte Themen, sowie erkennbare und benennbare Kunstwerke aus dem Oeuvre des Verstorbenen/Geehrten - Figuren aus Gemälden, Skulpturen, literarische Szenen, literarische Figuren, Musikstücke - werden ihren Schöpfer betrauern und/oder rühmen.

\footnotetext{
${ }^{11}$ Hierzu und zum folgenden: HAUSDORF 2011 (wie Anm. 10), S. $173 \mathrm{ff}$.

${ }^{12}$ Ibidem, S. 176 f, 181.
}

${ }^{13}$ Ibidem, S. 176, 184.

${ }^{14}$ Einen Überblick über Trauerfiguren des 19. und frühen 20. Jhs. gibt: GÖTZ, A. M.: Die Tranernde. Weibliche Grabplastik und bürgerliche Trauer um 1900. Köln - Weimar - Wien 2013. 


\section{Rühmende und trauernde Kunstwerke im französischen Grabmal des 19. Jahrhunderts}

Alain Bonnets Aufsatz über französische Künstlerdenk- und -grabmäler zufolge sind die beigegebenen Kunstwerke Zeichen, die jeweils metonymisch für das Oeuvre des Künstlers insgesamt einstehen. ${ }^{15}$ In der Mehrzahl der Fälle kommt man mit dieser Bestimmung gut zurecht. In einigen Fällen aber entwickelt das wiederholte Kunstwerk eine Aktivität, die sich nicht länger zeichentheoretisch beschreiben lässt, die das Zitatsein hinter sich lässt, die das repetierte Kunstwerk in neuer (gelegentlich beunruhigender Weise) wirklich werden lässt. Als spätes, schon ins beginnende 20. Jh. gehörige Beispiel soll das von Bonnet ins Spiel gebrachte Grabdenkmal für den Maler Jean-Baptiste Greuze diese Beunruhigung illustrieren, ${ }^{16}$ Beunruhigung, die sich einstellt, weil das memorierte Kunstwerk sich soweit aus seinem ursprünglichen Kontext freisetzt, dass es auf geradezu unheimliche Weise lebendig wird. (Abb. 5) Im Bildgedächtnis der Nachwelt verband sich mit dem Künstler Greuze vor allem ein Gemälde, das ein schönes Mädchen zeigt - mit leicht derangiertem Oberteil. Sie trägt einen zerbrochenen Krug, eine Beschädigung, die offensichtlich für ihr trauriges Gesicht verantwortlich ist. Kennt man die ikonographische Tradition (die noch Heinrich von Kleists Lustspiel „Der zerbrochne Krug“" grundiert) erschließt sich der erotische Hintersinn des Gemäldes. Es ist adressiert an einen Betrachter, der vielleicht vor dem Gemälde gleich Diderot vor Greuzes „Mädchen, das sein totes Vögelchen beweint" den Wunsch hegt, „die Ursache Ihres Kummers zu sein. ${ }^{“ 17}$ In Ernest Dagonets Grabmal für Greuze auf dem Montmartre-Friedhof trauert das zur lebensgroßen Bronzefigur monumentalisierte „Mädchen mit dem zerbrochenen Krug" nicht mehr um das Mißgeschick des Zerbrechens des Kruges und nicht mehr um das in dieses Missgeschick allusiv verpackte

\footnotetext{
${ }^{15}$ BONNET 2008 (wie Anm. 4), S. 24.

${ }^{16}$ Zur Geschichte des Grabmals: BONNET 2008 (wie Anm. 4), S. 25.

17 Diderot \&o l'Art de Boucher à David: Les Salons 1759-1781, Katalog der Ausstellung, Paris, Monnaie 1984-1985, Paris 1984,
}

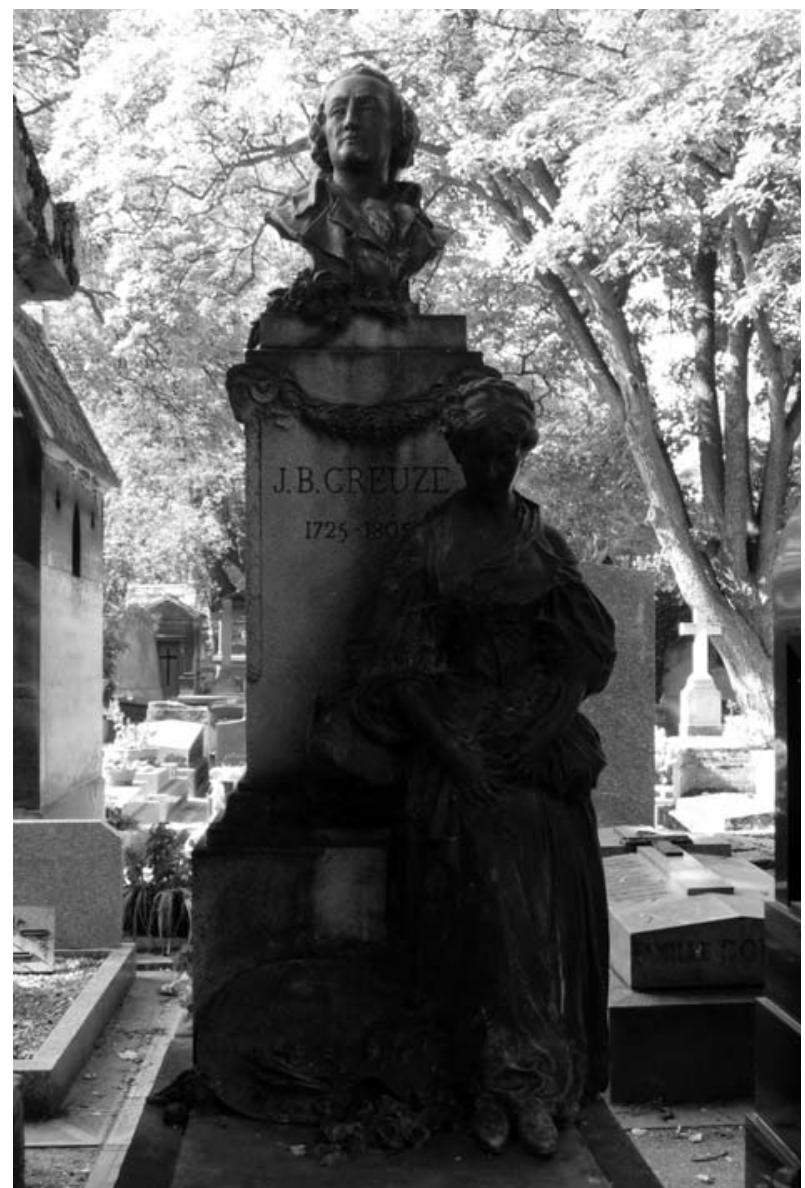

Abb. 5: Dagonet, Ernest, Grabmal für Jean-Baptiste Greuze, 1909, Paris, Cimétière de Montmartre (Foto: Hans Körner)

Trauern über den Verlust der Unschuld; sie trauert über den Tod ihres Malers. Diese „Pleureuse“ weist zeitlich über Hans Scherpes Anzengruber-Grabmal hinaus. Die Vorraussetzungen für beide Lösungen liegen im frühen 19. Jh.

Das früheste Künstlergrabmal auf dem PèreLachaise, das ein Kunstwerk des Verstorbenen im

S. 237, 239. Vgl. KÖRNER, H.: „Das Mädchen mit dem zerbrochenen Krug" und sein Betrachter. Zum Problem der Allegorie im Werk des Jean-Baptiste Greuze. In: Empfindung und Reflexion. Ein Problem des 18. Jabrbunderts (= Münchner Beiträge zur Geschichte und Theorie der Künste, I). Eds.: KÖRNER, H. - PERES, C. - STEINER, R. - TAVERNIER, L. Hildesheim - Zürich - New York 1986, S. 239-272. 


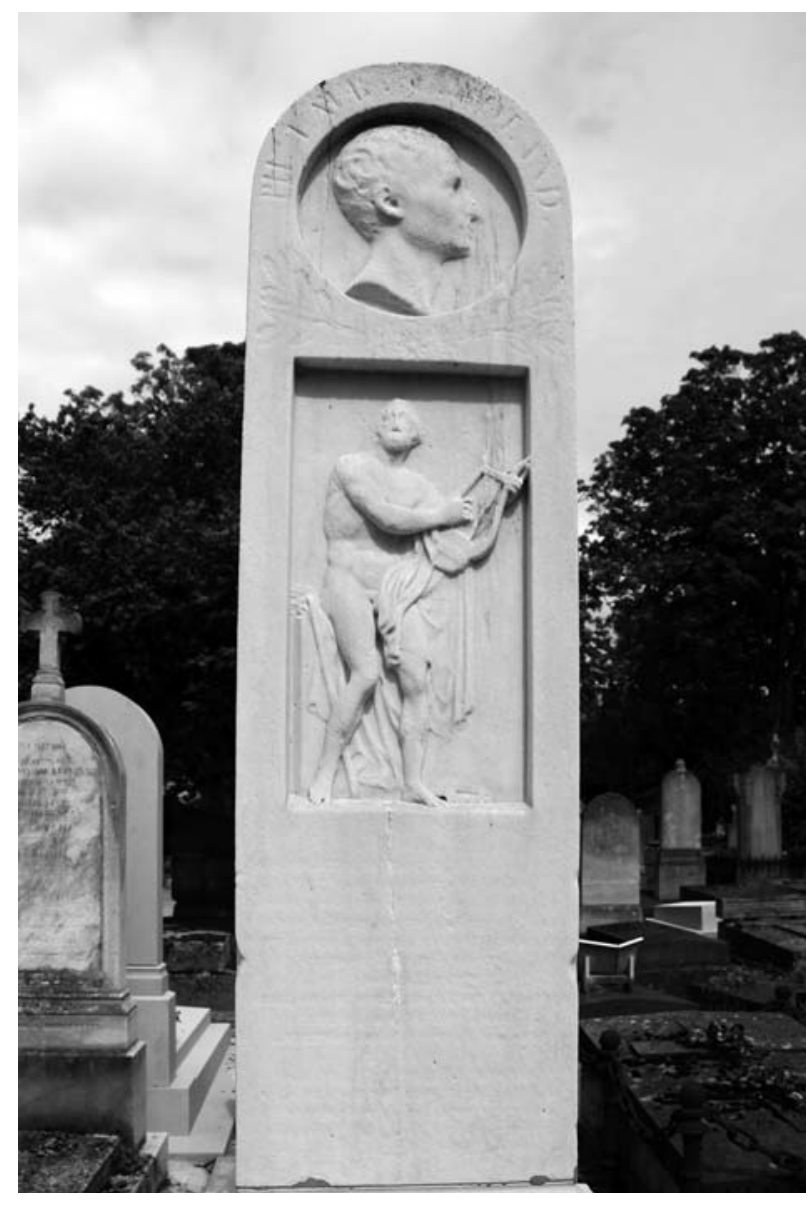

Abb. 6: David, d'Angers, Pierre-Jean / Caillouette, Lonis-Denis, Grabmal für Philippe-L aurent Roland, 1816 oder wenig später, Paris, Cimetière du Père-Lachaise (Wikimedia Commons. Foto: Pierre-Yves Beaudouin)

Bild thematisiert, gehört überhaupt zu den frühen Grabmälern mit bildlicher Ausstattung auf den neuen (zunächst) außerstädtischen Friedhöfen. ${ }^{18}$ Der Bildhauer Philippe-Laurent Roland war 1816 in seinem Atelier vom Tod überrascht worden. Zwei seiner Schüler besorgten die bildliche Ausstattung der Grabstele auf dem Père-Lachaise. (Abb. 6, 7) Pierre-Jean David d'Angers schuf das Porträt des Lehrers, Louis-Denis Caillouette transponierte ein Hauptwerk des Verstorbenen, den blinden, seine

${ }^{18}$ LE NORMAND-ROMAIN, A.: Mémoire de marbre. La sculpture funéraire en France 1804-1914. Paris 1995, S. 310. Antoinette Le Normand-Romain gab einen Überblick über die Zuord-

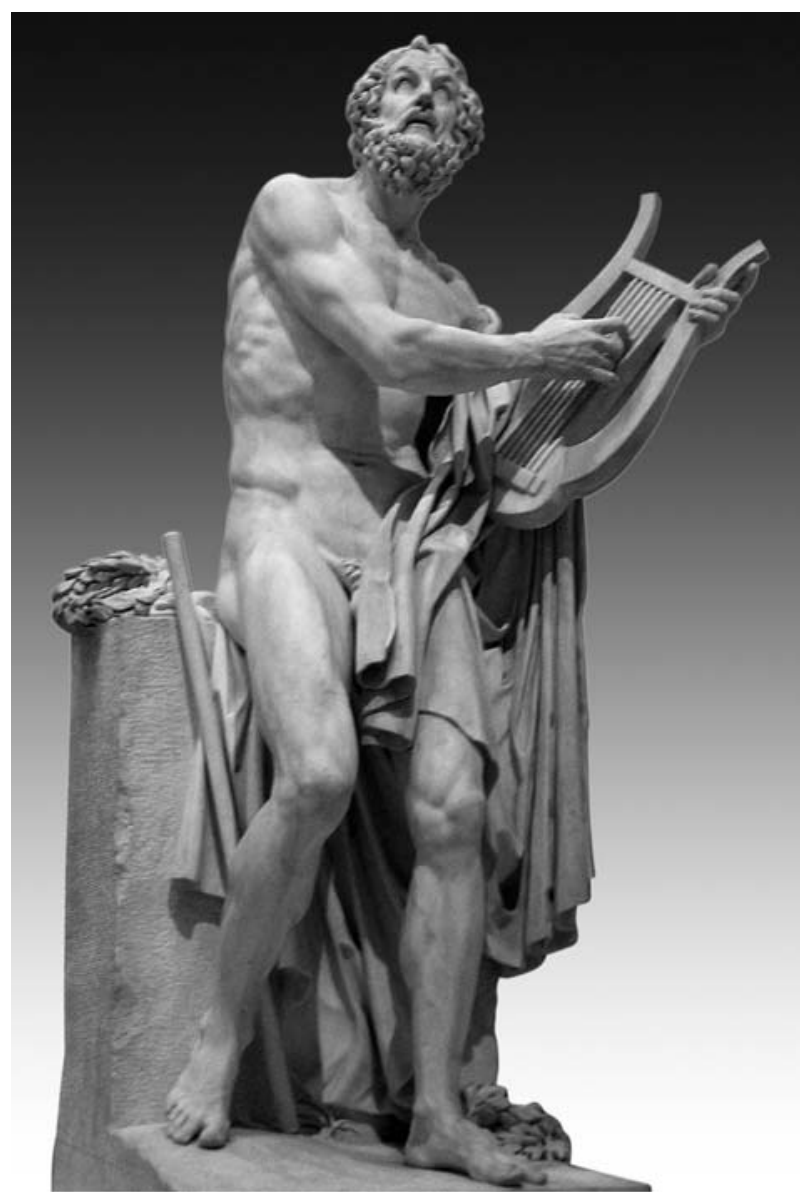

Abb. 7: Roland, Philippe-Laurent, Homer, 1812, Paris, Musée du Louvre (Wikimedia Commons. Foto: Urban)

Dichtungen singenden Homer - die Statue war 1812 vollendet und 1814 auf dem Salon ausgestellt gewesen -, in das Medium des Reliefs. Annähernd gleichzeitig mit dem Bildhauer Roland dürfte Antoine Parmentier sein Grabmal auf dem Père-Lachaise erhalten haben. Reliefs halten die Lebensleistung des Pharmazeuten und Agrarwissenschaftlers fest - sie bilden landwirtschaftliche Gerätschaften und Früchte ab, um deren Erforschung und Anbau Parmentier sich verdient gemacht hatte. ${ }^{19}$ Vorausge-

nung von Kunstwerken zum Künstlergrabmal in Frankreich. Ibidem, S. $310 \mathrm{ff}$.

${ }^{19}$ Ibidem, S. 60. 
gangen waren Reliefs auf Denkmälern von Militärs. Napoleons General Desaix wurde 1802 in Straßburg ein Denkmal gesetzt. Den Tod Desaix', der dank seines Eingreifens die fast sichere Niederlage gegen die österreichische Armee in den kriegsentscheidenden Schlachtensieg wenden konnte, erinnert eines der Landolin Ohnmacht verdankten Reliefs auf dem sarkophagähnlichen Zwischenstück zwischen hohem Sockel und Trophäe; die anderen drei Reliefs rühmen zwei weitere militärische Leistungen Desaix' und lassen ihn von Mars und Bellona bekrönen. ${ }^{20}$ Die im Relief zitierte künstlerische Leistung des verstorbenen Künstlers Roland unterscheidet sich davon zunächst nicht grundsätzlich. Doch ein zweiter Rahmen ist virtuell eingezogen. Die Reliefs am Grabmal für Parmentier sind emblematisch; die Schlachtenbilder am Denkmal für General Desaix sind narrativ und in Hinblick auf die Darstellung der Krönung des Helden allegorisch. Das memorierte Kunstwerk am Künstlergrabmal Rolands ist demgegenüber zuerst und zunächst das Bild eines Bildes. Der ,zweite Rahmen' markiert, dass die primäre Bedeutung des Reliefs am Grabmal für Roland im Kunstwerk-Sein liegt. Abgebildet ist zunächst nicht der blinde Sänger Homer, sondern das Meisterwerk Rolands. Diese vom Medienwechsel unterstützte Neukontextualisierung lässt die inhaltliche Aussage der Skulptur nicht unberührt. Der inspiriert nach oben gewendete Kopf des blinden Sängers wendet sich dem Medaillon-Bildnis des Verstorbenen zu; Homer singt jetzt zu Ehren Rolands.

Wie Erwin Panofsky in einem berühmt gewordenen Aufsatz dargelegt hat, bereitete Nicolas Poussins spätere Version seines „Et in arcadia ego“ zwar in der Bildstimmung Goethes nostalgisches „Auch ich war in Arkadien" vor, bezieht sich grammatikalisch korrekt jedoch auf den Tod, der zuvor bei Guercino und in der früheren Version des Themas bei Poussin noch mit dem Totenschädel auf dem Sarkophag sichtbar anwesend ist und Erschrecken auslöst. Auch in Arkadien ist das Leben endlich. In

\footnotetext{
${ }^{20}$ https://fr.wikipedia.org/wiki/Landolin_Ohmacht (16. 10. 2015).

${ }^{21}$ PANOFSKY, E.: „Et in Acadia ego“. Poussin und die Tradition des Elegischen. In: PANOFSKY, E.: Sinn und Deutung
}

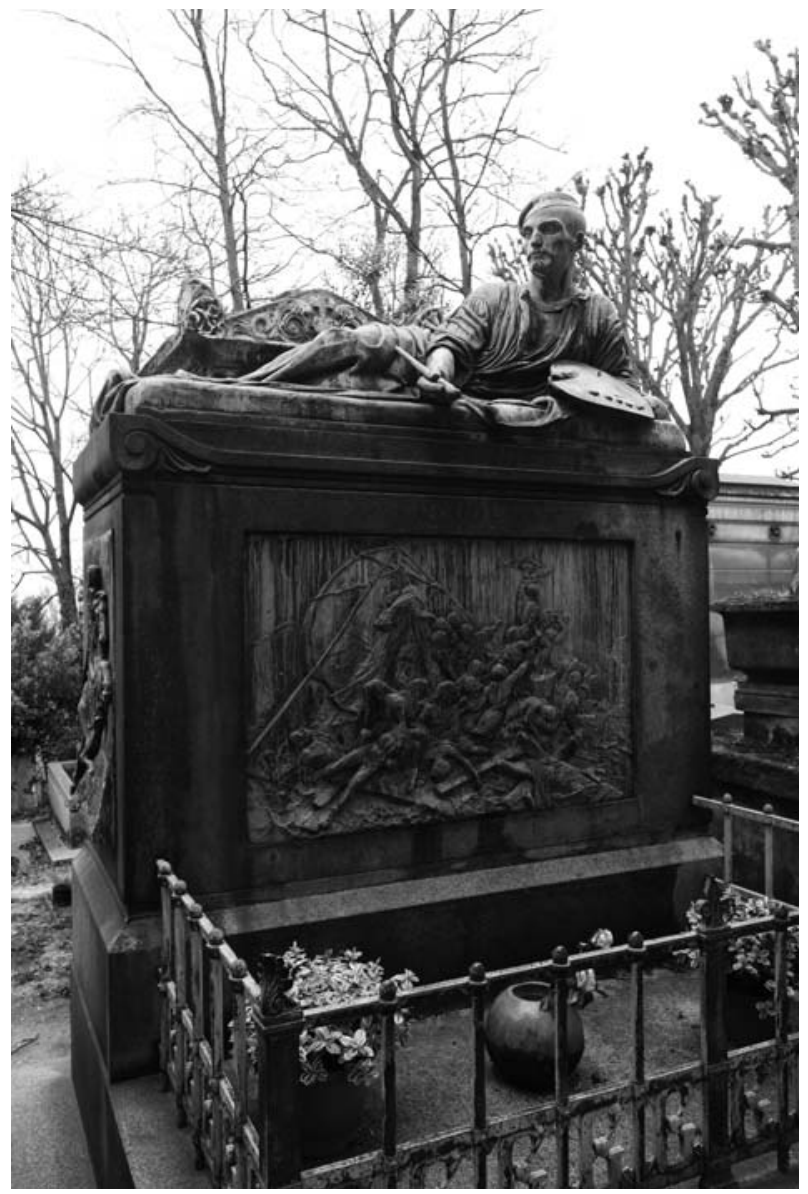

Abb. 8: Étex, Antoine, Grabmal für Théodore Géricault, 1841, 1884, Paris, Cimetière du Père-Lachaise (Foto: Hans Körner)

Poussins Version des Themas von um 1640 ist der Schrecken der Besinnlichkeit und der maßvollen Trauer gewichen. ${ }^{21}$ Chateaubriand, 1828-1829 französischer Botschafter in Rom, hielt diese elegische Weise, dem memento mori zu begegnen, für die angemessene Würdigung, als auf seine Veranlassung hin in der römischen Kirche S. Lorenzo in Lucina Nicolas Poussin ein Denkmal gesetzt werden sollte. ${ }^{22}$

in der bildenden Kunst (1957 engl.) Köln 1975, S. 315-377.

${ }^{22}$ LE NORMAND-ROMAIN 1995 (wie Anm. 18), S. 310; Bonnet 2008 (wie Anm 4), S. 24 f. 
Die melancholische Reflexion der Hirten und der Personifikation im Gemälde findet in Desprez' Übersetzung in das Relief unterhalb der Widmungsinschrift mit Poussin einen neuen Gegenstand, der aber nicht unbedingt aus dem Bild heraus führt. Poussin ließ in seiner Kunst Arkadien wieder lebendig werden. Für die Betrachter seines Kenotaphs durfte der Maler sich denen zugehörig fühlen, die in Arkadien waren und nun nicht mehr sind.

Antoine Étex wird ab der Mitte des Jahrhunderts dem Kunstwerk im Grabmal zu einer neuen, ,existenzielleren' Rolle verhelfen. Zunächst aber stablisierte Étex die junge Bildtradition, Künstler mit Reliefs ihrer Bildwerke zu bezeichnen und auszuzeichnen. Théodore Géricaults Grabfigur ist in seinem Grabmal auf dem Père-Lachaise als Bild eines Malers ausgewiesen, hier aktualisiert als Bild des noch auf dem Sterbelager künstlerisch Tätigen. ${ }^{23}$ (Abb. 8) Das Künstlersein Gericaults memoriert im Grabmal auf dem Père-Lachaise auch sein Hauptwerk. Das „Floß der Medusa" ist in Reliefform in die Vorderseite des Grabmalmonuments eingelassen. Das GéricaultGrabmal war von Étex bereits 1841 gefertigt, über dem Grab aufgestellt, bereits 1844 aber wegen Witterungsschäden wieder entfernt worden. Das aktuelle Grabdenkmal konnte erst 1884 in Bronze gegossen und auf den Père-Lachaise verbracht werden. Zusätzlich zum Materialwechsel kamen jetzt die Reliefs an den Schmalseiten des Grabmals mit Bronzereproduktionen zweier weiterer Gemälde des Verstorbenen. Die Einzelheiten der komplexen Entstehungsgeschichte dokumentierte Étex selbst in einer Buchpublikation. ${ }^{24}$

Ein zweites kleines Buch widmete Étex seinem 1852 verstorbenen Lehrer James Pradier. Der Text von Étex mündet in die Geschichte des Grabmals für Pradier ein, und der Eindruck ist nicht von der Hand zu weisen, Étex habe die Schrift seinem ver-

\footnotetext{
${ }^{23}$ Zur Entstehungsgeschichte des Grabmals: MANGEANT, P. E.: Antoine Étex, peintre, sculpteur et architecte. In: Réunion des Sociétés des Beaux-Arts des départements, 1894, S. 1363-1391, hier S. 1389 f., LE NORMAND-ROMAIN, A.: Tombeaux d'artistes. In: Revue de l'art, 74, 1986, S. 55-63, hier S. 56. Vgl. LE NORMAND-ROMAIN 1995 (wie Anm. 18), S. 310; BONNET 2008 (wie Anm. 4), S. 25; CHÉNIQUE, B.: La vie et l'oeuvre d'Antoine Étex (Mémoire de Maîtrise). o. O.1988, S. 19.
}

storbenen Lehrer nur gewidmet, um seine eigene (von der Familie des Künstlers zurückgewiesene) Konzeption des Pradier-Grabmals zu verteidigen. Verbittert klagte er einen Mitschüler im Atelier Pradiers an (Étex nannte ihn nicht; es handelt sich um Eugène-Louis Lequesne), sich bei der Familie Pradiers eingeschmeichelt und Étex' Grabmalskonzept intrigant zu Fall gebracht zu haben. Étex hatte eine Gemeinschaftsarbeit der Pradier-Schüler geplant. Sie sollten mittels allegorischer Figuren die Qualitäten des Meisters verkörpern. Außerdem sollten Hauptwerke des Verstorbenen in einem Fries die Kunst Pradiers erinnern. Das schlussendlich 1853 von Lequesne und Simart, gemeinsam mit dem Architekten Garnaud ausgeführte Grabmal (Abb. 9) ist so weit von Étex' Idee nicht entfernt. Auf der Stele angebrachte Flachreliefs wiederholen Werke Pradiers. Abgeschlossen wird die Stele durch eine hufeisenförmig gerahmte Nische mit der Büste des Toten. Hier ist die Abweichung von Étex' Konzeption am größten: Étex sah als Bekrönung des Grabmals Pradiers „Sappho“, vor. (Abb. 10) Ein vergoldeter Bronzeguss des Marmorbildwerk sollte sich über dem Sockel mit Reliefs anderer Werke Pradiers erheben. ${ }^{25}$

In den Legenden, die sich um die griechische Lyrikerin Sappho Lyrikerin ranken, wird ihre Liebe zu Frauen hervorgehoben. ${ }^{26} \mathrm{Zu}$ Tode soll sie aber die Neigung zu einem Mann gebracht haben. Sappho, wie zuerst von Meander erzählt und später in dem von Ovid fingierten Abschiedsbrief der Dichterin ausgeführt, liebte den schönen Fährmann Phaon. Als der ihre Liebe verschmähte, stürzte sie sich vom Leukadischen Felsen ins Meer und in den Tod. Man darf annehmen, dass Pradiers Darstellung die düstere Reflektion der Zurückgewiesenen meint, die dem Selbstmord vorausgeht. Im Todesjahr des Bildhauers 1852 wurde die Marmorskulptur der „Sappho“ auf

\footnotetext{
${ }^{24}$ ÉTEX, A.: Les trois tombeaux de Géricault 1837-1884. Paris 1885.

${ }^{25}$ ÉTEX, A.: J. Pradier. Étude sur sa vie et ses ouvrages, Paris 1859, S. 43 f. Zur Entstehung des Grabmals: LE NORMAND-ROMAIN 1986 (wie Anm. 23), S. 55 f., Vgl. LE NORMAND-ROMAIN 1995 (wie Anm. 18), S. 310 f.
}

${ }^{26}$ Vgl. http://de.wikipedia.org/wiki/Sappho (7. 4. 2015). 


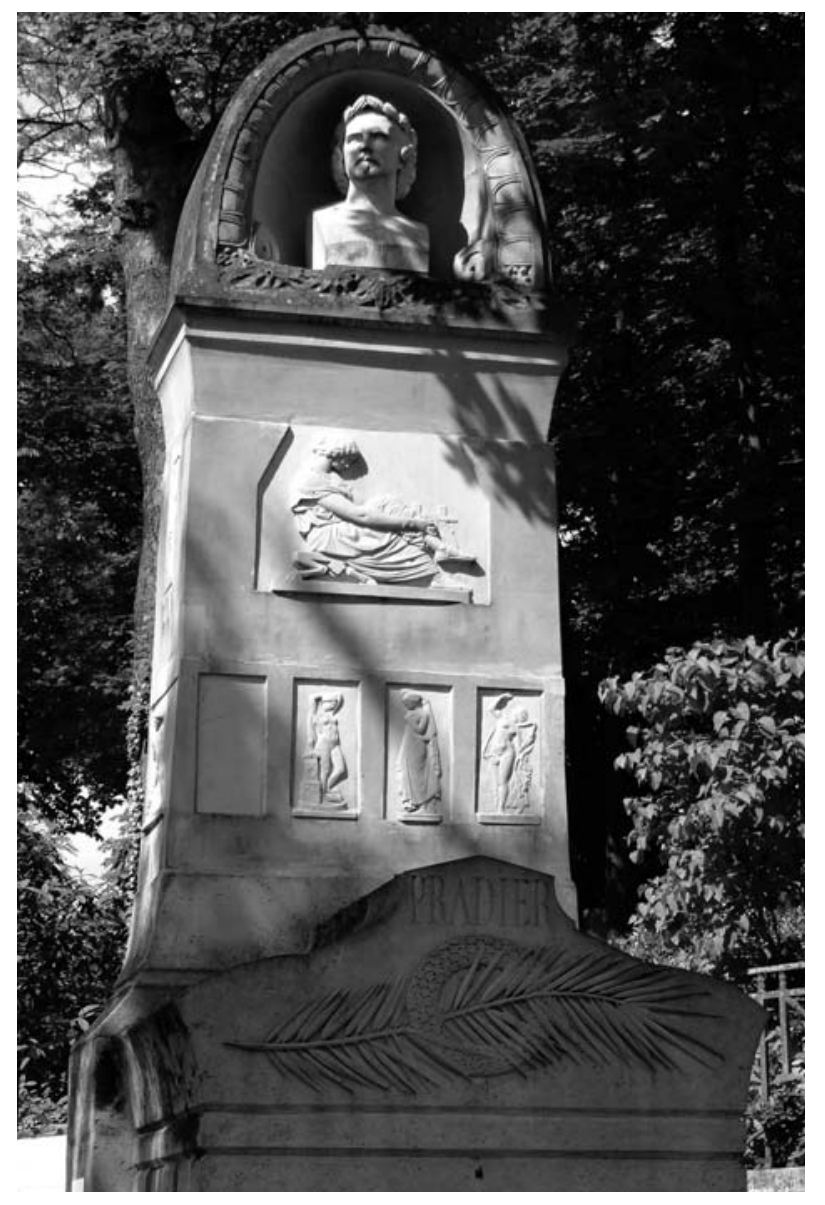

Abb. 9: Lequesne, Eugène-Louis / Simart, Pierre-Charles (Reliefs) / Garnaud, Antoine-Martin (Archit.), Grabmal für James Pradier, 1853, Paris, Cimetière du Père-Lachaise (Wikimedia Commons. Foto: MOSSOT)

dem Pariser Salon gezeigt. ${ }^{27}$. Das nur wenige Monate zurückliegende unerwartet frühe Sterben des Künstlers, hatte dem Salonexponat besondere Aufmerksamkeit beschert. „Sappho“, war Pradiers letztes bedeutendes und großformatiges Werk, und mit ihm behandelte Pradier ein ernstes Thema, fernab vom frivolen Genre, das Pradiers Bewunderer begeistert und seine Widersacher verurteilt hatten. (Abb. 11) Auch Lequesne räumte dieser Figurenerfindung des Lehrers einen prominenten Platz ein: an der Vorder-

\footnotetext{
${ }^{27}$ Eine Bronzeversion der stehenden Sappho in halber Größe war vier Jahre vorher bereits ausgestellt gewesen. GIELLY,
}

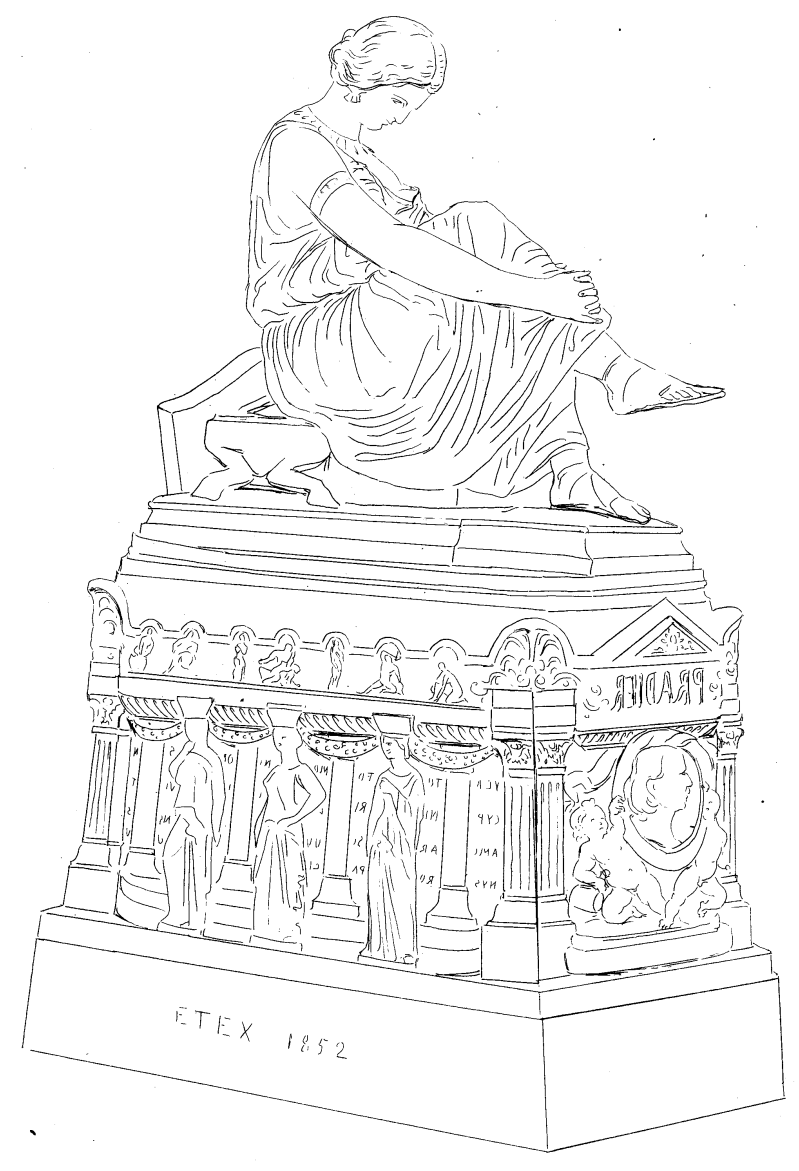

Abb. 10: Étex, Antoine, Grabmal für James Pradier (Projekt), 1852 (Bildritat: Étex, Atoine, J. Pradier. Etude sur sa vie et ses ouvrages, Paris 1859)

seite der Stele, unter dem Bildnis Pradiers und über den anderen Reliefs. „Sappho“ in der Konzeption von Étex hätte demgegenüber das Grabmonument bekrönt, und sie wäre vollplastisch und wohl lebensgroß gewesen. In dieser Form wäre Sappho eine sehr andere Beziehung zum Verstorbenen eingegangen. Im Unterschied zum Relief auf der Stele des ausgeführten Grabmals, das das Bildwerk nur zitiert, hätte Sappho in dem von Étex konzipierten Monument emotionale Beziehung zum Verstorbenen aufgenom-

L.: Les Pradier du Musée de Genève. In: Genava, 1925, S. 347-357, hier S. 354. 


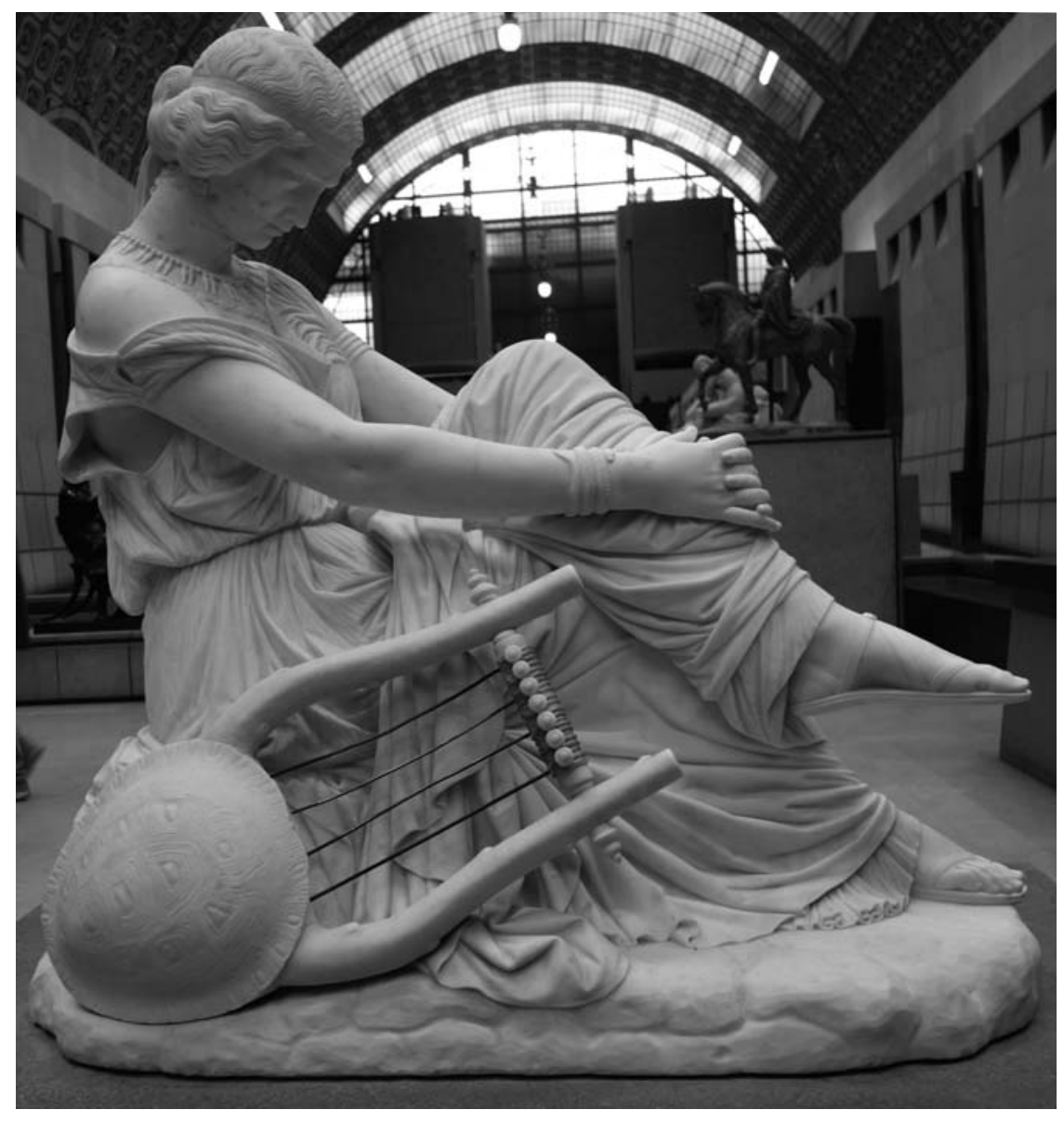

Abb. 11: Pradier, James, Sappho, 1852, Paris, Musée d'Orsay (Foto: Hans Körner)

men. Aus einer Abbildung einer Skulptur Pradiers wäre eine Trauerfigur geworden. Das Kunstwerk Pradiers selbst hätte sich emanzipiert und als Kunstwerk im Grabmalskontext engagiert. Nicht die antike Sappho hätte getrauert, sondern Pradiers „Sappho“ hätte über den Tod ihres Schöpfers getrauert.

Théophile Gautier gemahnte in seiner Besprechung des Salons von 1852 die Plinthe, die die Skulptur trägt, an eine Grabplatte, und er warf die Frage auf, ob Sappho nicht eigentlich ihren Schöpfer beweine. ${ }^{28}$ Dementsprechend ließ Georges Bell in

\footnotetext{
${ }^{28}$ GAUTIER, TH.: Critique d'Art. Extraits des Salons (1833-1872). Ed.: GIRARD, M.-H. (= Collection Écrits sur l'art). Paris 1994, S. 346.
}

seinem Nachruf auf Pradier die Leser gemeinsam mit der Skulptur der Sappho den Tod Pradiers betrauern. ${ }^{29}$ Graf von Nieuwerkerke, der als Generaldirektor des Louvre für die Organisation der Salonausstellung zuständig war, hatte die Statue bereits als „Pleureuse“ inszeniert. Die Lyra der Dichterin umkleidete er mit schwarzem Tuch. ${ }^{30}$ Diese Inszenierung und die entsprechende Rezeption in der Kunstliteratur ist in Étex' Projekt monumentalisiert. Eine fundamentale Neubestimmung wäre damit vorgenommen worden. Étex' Grabmal für Pradier,

${ }^{30}$ LAPAIRE, C.: James Pradier (1790-1852) et la sculpture française de la génération romantique. Catalogue raisonné. Zürich - Lausanne - Mailand 2010, S. 393.

\footnotetext{
${ }^{29}$ BELL, G.: Pradier. Paris 1852, S. 21.
} 
hätte, wäre es realisiert worden, vor Augen geführt, was ein Kunstwerk von sich her tun kann, wenn es neu verortet wird. ${ }^{31}$

\section{Die weibliche Trauerfigur als „allegorie réélle“}

$\mathrm{Zu}$ dem als Gemeinschaftswerk des Architekten der Hochschule und von Studienkollegen des gefallenen Malers geschaffenen Denkmal für Henri Regnault im Innenhof der École des Beaux-Arts in Paris steuerte Henri Chapu eine Trauerfigur bei, die außerordentliche Bewunderung erregte, wiederholt in unterschiedlichen Kontexten von Chapu selbst reproduziert wurde und die zahlreiche Trauernde und Rühmende an französischen Denk- und Grabmälern der folgenden Jahrzehnte nachhaltig beeinflusste. ${ }^{32}$ (Abb. 12) Auch insofern wurde Chapus "Jugend" wirkmächtig, als diese Allegorie zumindest in der Rezeption zu einer individualisierten Trauerfigur konkretisiert worden war: zu Regnaults Verlobter Geneviève Bréton, die nicht zuletzt dank der von ihr selbst ritualisierten Opferrolle zur Verkörperung des nach dem verlorenen Krieg von 1870/71 trauernden und das Wiedererstarken der gedemütigten Nation garantierenden ,jungen Frankreichs“ aufgestiegen war. ${ }^{33}$

Der Einfluss von Chapus ,Jeunesse" für Grabmal und Denkmal machte sich im deutschsprachigen Raum in den Jahren um 1900 nachdrücklicher geltend. Zum Denkmal für Anton Bruckner in Wien (1899) steuerte Fritz Zerritsch die Muse bei, die ähnlich be- resp. entkleidet ist wie das Vorbild in der Ecole des Beaux-Arts, die wie die "Jugend" Chapus das rechte, jetzt das linke Knie auf den unteren Absatz der Stele auflegt, die allerdings noch extatischer beide Arme zum bronzenen Büstenporträt hin ausbreitet. Besinnlicher demgegenüber die Trauerfigur, die an einem Grabmal in den Nordarkaden des Innsbrucker

\footnotetext{
${ }^{31}$ Allgemein zu der sich von künstlerischen Intentionen und von Auftraggeberseite her vorgeschriebenen Funktionen freisetzenden Eigenaktivität von Bildwerken: BREDEKAMP, H.: Der Bildakt. Frankfurter Adorno-Vorlesungen 2007. Neufassung 2015, (2010). Berlin 2015.

${ }^{32} \mathrm{Zu} \mathrm{dem} \mathrm{Denkmal} \mathrm{in} \mathrm{der} \mathrm{École} \mathrm{des} \mathrm{Beaux-Arts} \mathrm{im} \mathrm{allgeme-}$ inen, zu Chapus „Jeunesse“ im besonderen, sowie zu der immensen Nachwirkung von Chapus Figurenerfindung: KÖRNER, H.: Die ,Jugend" und der tote Held. Das Denkmal
}

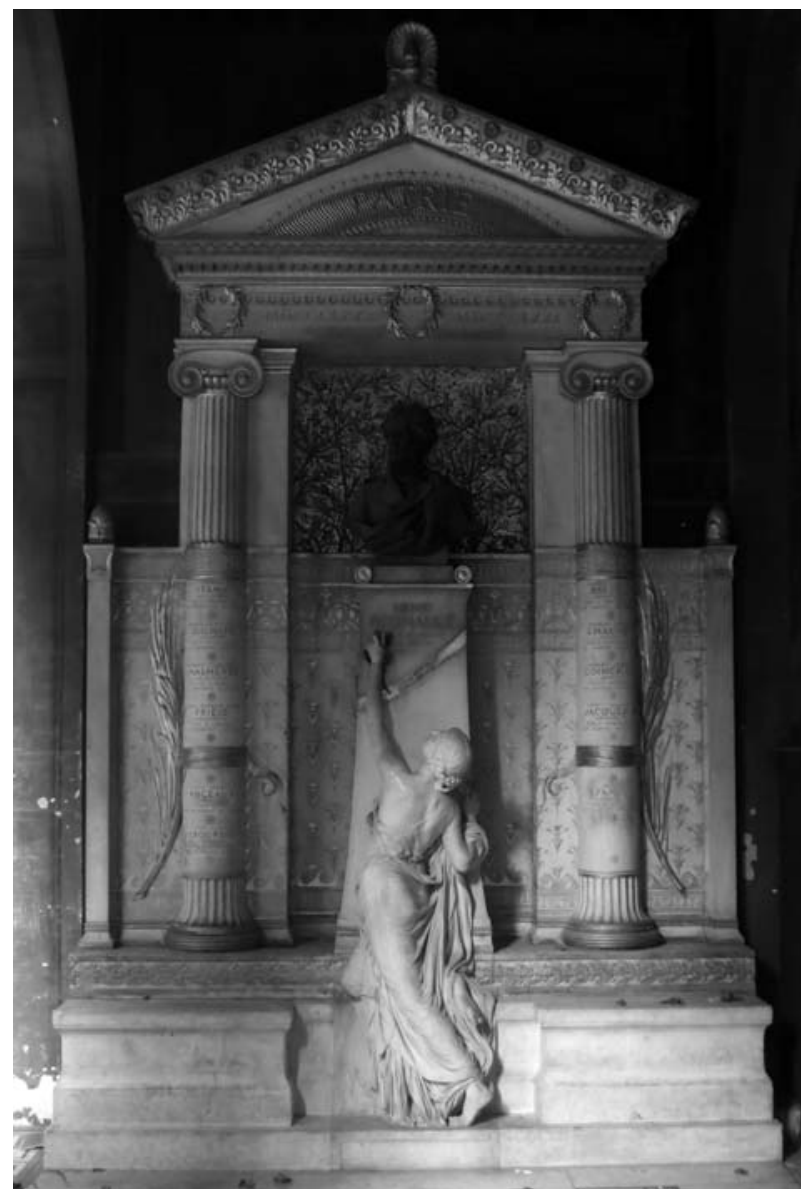

Abb. 12: Coquart, Ernest / Pascal, Jean-Louis (Architekten) / Chapu, Henri-Michel-Antoine (Jugend) / Degeorge, Charles-Jean-Marie (Büste) u. a., Denkmal für Henri Regnault, 1876, Paris, Ecole des Beaux-Arts (Cours du Mûrier (Foto: Hans Körner)

Westfriedhofs die Namen der hier bestattete Familien Hörandtner und Nagele auf den Grabstein schreibt. Diese beiden österreichischen Adaptionen von Chapus Figur ${ }^{34}$ sind erst nach Scherpes Trauerfigur für

für Henri Regnault in der École des Beaux-Arts, Paris (= Düsseldorfer Kunsthistorische Schriften, Band 12), Düsseldorf 2016.

${ }^{33}$ Ibidem, S. 38 ff.

${ }^{34}$ Dass Chapus ,Jeunesse“ grundsätzlich Modellcharakter für viele erotisierten Trauerfiguren hatte, darauf wies bereits Barbara Haubold im Zusammenhang mit der Besprechung des Grabengels am Wiener Grabmal für Arnold Böhm († 1903) 


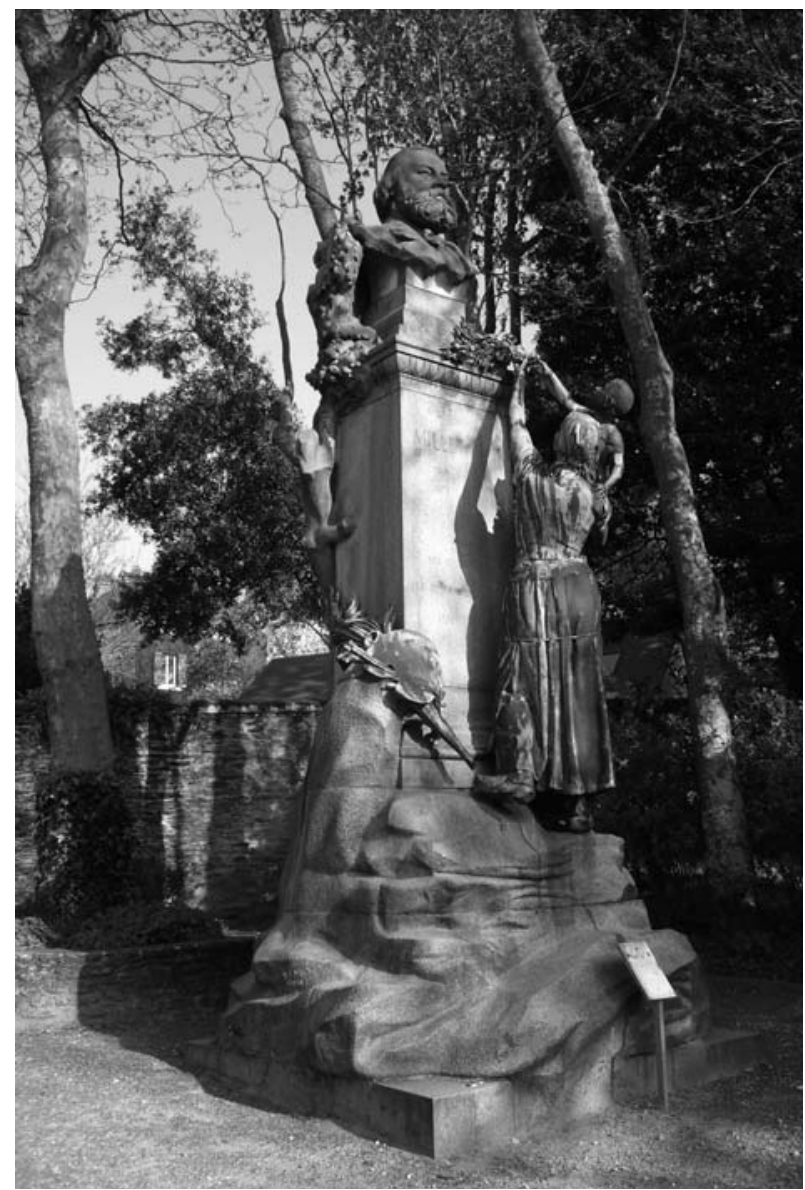

Abb. 13: Chapu, Henri (vollendet von Boutellier, Jean-Ernest nach Chapus Tod), Denkmal für Jean-François Millet, 1892, Cherbourg-Octeville (Wikimedia Commons. Foto: HaguardDuNord)

Anzengruber entstanden und sind möglicherweise indirekt darüber vermittelt. Sie bleiben im ikonographisch traditionellen Rahmen. Spannender ist Scherpes Lösung, die das Konkretisierungspotential des Pariser Vorbilds nutzt, und die Trauerfigur / Muse mit einer literarischen Figur des Verstorbenen identifiziert.

hin. HAUBOLD, B.: Die Grabdenkmale des Wiener Zentralfriedhofs von 1874 bis 1918 (= Kunstgeschichte: Form und Interesse, Bd. 30). München 1990, S. 32. Die Entsprechungen sind in diesem Fall allerdings sehr ungefähre.

${ }^{35}$ LUIS, E.: De places en jardins. La statuaire dans l'espace publique de la Manche 1800-1945. o. O. 2007, S. 85, 87.
Entsprechungen für diese Konkretisierung und insbesondere für den Modus des Volkstümlichen finden sich in der französischen Kunst. Zu den freien Adaptionen der Allegorie der „Jugend“ am Regnault-Denkmal im Oeuvre Chapus selbst zählt sein letztes Werk: das bei Chapus Tod 1891 unvollendet zurückgelassene und von Boutellier im Folgejahr vollendete Denkmal für den Maler Jean-François Millet in Cherbourg. (Abb. 13) Chapu hatte anfänglich eine Allegorie der Malerei vor der Büste des Verstorbenen erwogen. Er entschied sich schließlich um: unterhalb der Büste steht jetzt eine Bäuerin mit ihrem Kind, die Gaben des Feldes (anstelle des Lorbeerzweigs, den die ,Jugend“ darbringt) der Büste des Malers hochreicht. ${ }^{35}$ Die dem Sockel mitgegebenen Attribute der Malerei wachsen allein durch das gemeinsame Bronzematerial mit der das Gesamtwerk Millets stellvertretenden Bäuerin zu einer nun allerdings „realistischen“ Allegorie der Malerei zusammen. Es sind die Kunstwerke Millets, vertreten durch die bäuerliche Mutter, die den Maler ehren. Das Denkmal für den Maler von Barbizon wurde am 22. September 1892 enthüllt, im Jahr vor dem Grabdenkmal für Ludwig Anzengruber, in dem ebenfalls eine Bäuerin den verstorbenen Dichter des bäuerlichen Lebens betrauern wird.

Eine zweite, im selben Jahr 1892 fertiggestellte Figur, jetzt eine als bretonische Fischerin konkretisierte „Pleureuse“, ist hinzuzunehmen, wenn man nach französischen Analogien zu Scherpes ländlicher Trauerfigur auf dem Wiener Zentralfriedhof fragt: das Grabmal für den Maler Augustin Feyen-Perrin († 1888), dessen figürliche Ausstattung dem Bildhauer Ernest-Charles-Démosthène Guilbert verdankt ist. (Abb. 14) Für Guilberts Grabfigur auf dem Cimetière de Montmartre war eine Allegorie der Trauer vorbildhaft, die neben Chapus „Jugend“ ebenfalls zu einer Leitfigur der Grabplastik des späteren 19. Jhs. wurde: ${ }^{36}$ Henry Murgers Grabdenkmal auf dem „Cimetière de Montmartre" bereichert das Personal

${ }^{36}$ BELDIMAN, I.: Les commanditaires roumaines du monuments funéraires au XIXe siècle et leur orientation vers l'école francaise de sculpture, I. In: Revue roumaine d'bistoire de l'art, Série Beaux-Arts, XXXIX-XL, 2002-2003, S. 69-100, hier S. 92. 


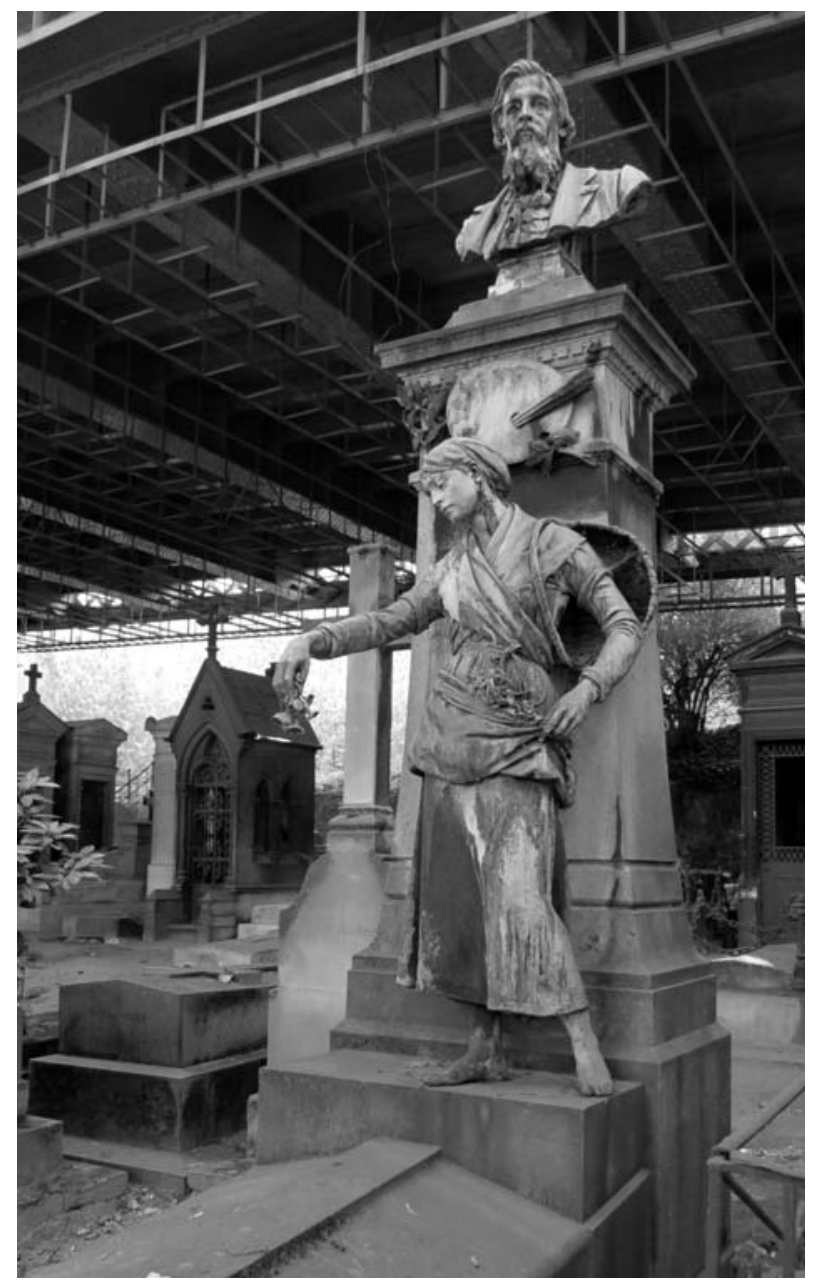

Abb. 14: Guilbert, Charles-Démosthène, Grabmal für Augustin Feyen-Perrin, 1892, Paris, Cimetière de Montmartre (Foto: Hans Körner)

\footnotetext{
${ }^{37}$ Dazu und zum Zusammenhang mit Guilberts Trauerfigur für das Grabmal für Feyen-Perrin: LE NORMAND-ROMAIN 1995 (wie Anm. 18), S. 278, 364; BELDIMAN 2002-2003 (wie Anm. 36), S. $91 \mathrm{f}$.

${ }^{38}$ VOTTERO, M.: La peinture de genre en France après 1850. Rennes 2012, S. $218 \mathrm{f}$

${ }^{39}$ Nur angemerkt an dieser Stelle sei die Grabfigur Louis-Ernest Barrias' für das Grab des Malers Gustave Guillaumets, der sich auf orientalische Themen spezialisiert hatte. (Ausstellung des Wachsmodells 1890 auf dem Salon) Das „Mädchen aus Bou-Saada" kauert auf der Grabplatte und streut Blumen auf das Grab. Es erinnert an eine Wolle spinnende Mädchenfigur aus einem Gemälde Guillaumets. Die interpikturellen Bezüge verkomplizieren sich dadurch, dass Barrias mit dieser Figur
}

der in Paris üblichen Trauerfiguren um eine neue Gebärde. Aimé Millet schuf die lebensgroße Figur der Muse der Lyrik, Erato, die sich auf einem Sockel über das Grab erhebt und von oben Blumen herabstreut. ${ }^{37}$ Guilbert memorierte - traditionell - den verstorbenen Maler Feyen-Perrin durch eine Büste auf der Grabmalsstele. Davor streut eine ländlich gekleidete junge Frau Blumen auf das Grab. Doch es ist nicht mehr eine Muse, wie im Grabmal für den Dichter Murger, auch keine allgemeine Allegorie der Kunst mehr, sondern eine „Cancalaise“. Der Maler Augustin Feyen-Perrin, der die Sommermonate in der kleinen Hafenstadt Cancal zu verbringen pflegte, hatte sich spezialisiert auf Darstellungen des einfachen Lebens an der bretonischen Küste. ${ }^{38}$ Die "Cancalaise“ ist Stellvertreterin aller bretonischen Bäuerinnen und Fischerinnen im Oeuvre FeyenPerrins, Stellvertreterin des bretonischen Genres im Oeuvre Feyen-Perrins im allgemeinen. ${ }^{39}$

\section{Das Ehrengrab für Ludwig Anzengruber auf dem Wiener Zentralfriedhof}

Am 10. Dezember 1889 war Ludwig Anzengruber in Wien verstorben. Eine schmerzhafte Entzündung, die er sich am 29. November, an seinem 50. Geburtstag, zugezogen hatte, führte zu der tödlichen Blutvergiftung. ${ }^{40}$ Rudolf Tyrolt erinnerte sich an das Begräbnis des Dichters: „Bei düsterem Nebelwetter trugen wir am 12. Dezember 1889 den Unvergeßlichen zur letzten Ruhestätte (...) Am selben Abend spielten wir im deutschen Volkstheater den „Pfarrer

ein eigenes älteres Bildwerk einer griechischen Spinnerin, „Das Mädchen aus Megara“ (1868/1870), orientalisierte. Dazu: JOUIN, H.: La Sculpture dans les cimetières de Paris. In: Nouvelles archives de l'art français, 3e sér. 4e année, XIII, 1897, S. 97-348, hier S. 239; LAFENESTRE, G.: Ernest Barrias (1841-1905). In: Revue de l'art ancien et moderne, XIII, 1908, S. 321-340, hier S. 322; LE NORMAND-ROMAIN 1986 (wie Anm. 23), S. 59; LE NORMAND-ROMAIN 1995 (wie Anm. 18), S. 317 f.; BLÜHM, A.: The Colour of Sculpture 1840-1910, Katalog der Ausstellung, Amsterdam, Van Gogh-Museum u. a. 1996-1997, Amsterdam - Zwolle 1996, S. 174; BONNET 2008 (wie Anm 4), S. 23.

${ }^{40}$ Zur Biographie Anzengrubers u. a.: BETTELHEIM, A.: Anzengruber. Der Mann - sein Werk - seine Weltanschaunng (= Geisteshelden (Führende Meister). Eine Sammlung 
von Kirchfeld“" ${ }^{41}$ Schon am Todestag war die Gründung eines Kuratoriums angeregt worden, das sich wenig später mit Rudolf Alt als Obmann konstituierte. Anton Bettelheim lieferte eine ausführliche Schilderung der Gründung und der Aktivitäten des Kuratoriums: der Versorgung der Kinder des Verstorbenen, dem Publikationsprojekt einer Gesamtausgabe, dem Engagement für die Aufführung von Anzensgrubers Bühnenstücken, schließlich der Finanzierung des Ehrengrabs auf dem Zentralfriedhof, der Konkurrenz um das Grabdenkmal und der Feier anlässlich der Einweihung am 29. Oktober 1893. ${ }^{42}$

Auf die Ausschreibung des „Clubs der Plastiker der Genossenschaft der bildenden Künstler Wiens“ hin reichten 18 Künstler Wettbewerbsmodelle ein. Vor den mit Preisen ausgezeichneten Projekten von Stephan Schwartz, Otto König und Johannes Benk wurde Hans Scherpe am 29. November 1890 zum Sieger des Preisausschreibens erklärt und mit der Schaffung des Grabdenkmals beauftragt. ${ }^{43}$ (Abb. 15) Bettelheim attestierte dem Grabmal „,künstlerisches Verdienst (...), dessen reiner, wahrhaft volkstümlicher Wirkung (...) kein Unbefangener sich verschließen kann." Die „,volkstümliche (...) Wirkung“ des Grabmonuments ist Bettelheim zufolge der Form der Grabstele und der jungen Bäuerin als Trauerfigur verdankt, deren Identifikation mit einer Figur aus einem von Anzengrubers Bühnenstücken oder Romanen später erörtert werden wird. Zunächst zur Form des Grabsteins. Bettelheim und andere charakterisierten den Grabstein als „Marterll $^{\text {‘44 }}$ Die Kritik Ludwig Hevesis, der „Marterlstil““

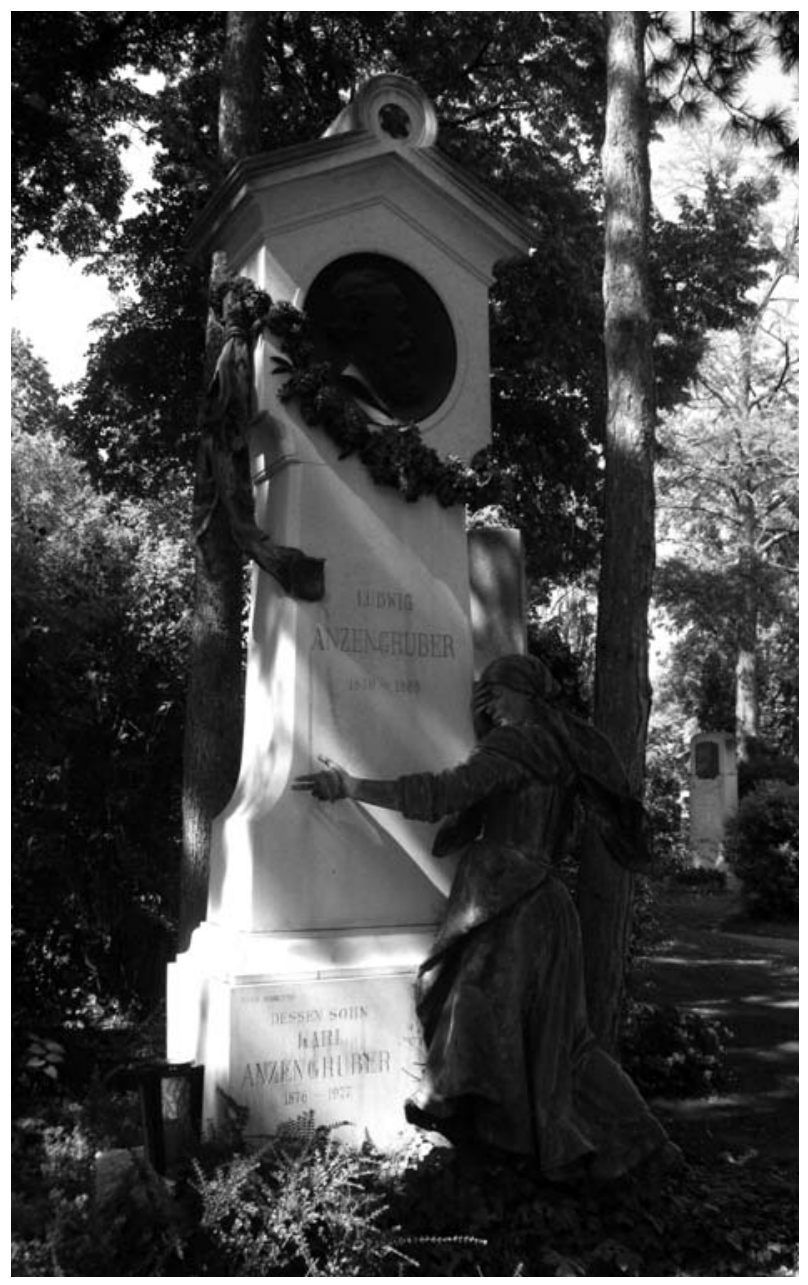

Abb. 15: Scherpe, Hans, Grabdenkmal für Ludwig Anzengruber, 1893, Wien, Zentralfriedhof (Wikimedia Commons. Foto: Andi oisn)

von Biographien, ed.: BetTelheim, A.). Berl in 1898 (2. Aufl.); BAUMER, F.: Ludwig Anzengruber. Vom Volkserzäbler zum Aufklärer und Realisten (= Stöppel-Kaleidoskop, 403: Reihe Kunst, Literatur), Weilheim 1989; CZEIKE, F.: Historisches Lexikon Wien, I. Wien 1992, S. 128 f., https://de.wikipedia. org/wiki/Ludwig_Anzengruber (25. 3. 2020)

${ }^{41}$ TYROLT, R.: Zum Tode Anzengrubers. In: Gedenkblätter an Ludwig Anzengruber. Zusammengestellt als Erinnerung an den 25. Todestag des großen Volksdichters. Ed.: BÖHM, F. J. Breslau 1915, S. 73-75, hier S. 74.

42 BETTELHEIM, A.: Das Anzengruber=Denkmal auf dem Wiener Central-Friedhofe. Rechenschaftsbericht, Wien 1893, o. S.; BETTELHEIM 1898 (wie Anm. 40), S. 280 ff. Vgl. HAUBOLD 1990 (wie Anm. 34), S. 85 ff.

${ }^{43}$ Zur Biographie Scherpes: Lexikon der bildenden Künstler von der Antike bis zur Gegenwart. Begründet von Ulrich Thieme u. Felix Becker, Bd. 39. Ed.: VOLLMER, H. München 1936, S. 36, http://www.aeiou.at/aeiou.encyclop.s/s200524.htm (20. 10. 2019), https://de.wikipedia.org/wiki/Johann_Scherpe (20.10.2019)

${ }^{44}$ BETTELHEIM 1893 (wie Anm. 42), o. S. Vgl. RIESENFELLNER, S.: Zwischen deutscher „Kulturnation“ und österreichischer „Staatsnation“. Aspekte staatlicher und nationaler Repräsentation in Dichter- und Musikerdenkmälern der Wiener Ringstraße bis zum Ersten Weltkrieg. In: Steinernes Bewußtsein I. Die öffentliche Repräsentation staatlicher und nationaler Identität Österreichs in seinen Denkmälern. Ed.: RIESENFELLNER, S. Wien - Köln - Weimar 1998, S. 269-303, hier S. 284. 
des Grabdenkmals für Anzengruber, sei „leider hinterher zu sehr akademisiert" worden, ${ }^{45}$ dürfte vor allem auf das antikisierende Abschlussgesims gemünzt gewesen sein. Hatte Scherpe ursprünglich eine einem ,richtigen’ „Martel“ besser vergleichbare Holzbedachung vorgesehen? So ähnlich jedenfalls sehen - von der genannten ,Akademisierung' abgesehen - die üblichen „Marterln“ aus, die v. a. im Alpenraum so zahlreich Brücken und Wege säumen. Sie halten Unglücksfälle in Erinnerung und mahnen die Vorbeigehenden, für die eines unversehenen Todes Gestorbenen Fürbitte zu leisten. ${ }^{46}$ „Marterln“ stehen deshalb nahe dem Unglücksort, selten aber unmittelbar am Unglücksort, denn ihre Funktion, zum Zweck der Linderung der Fegefeuerstrafen für die ohne Sterbesakramente zu Tode Gekommenen zum Gebet aufzurufen, erfüllen sie nur an häufiger begangenen Brücken und Wegen. ${ }^{47}$ Der Aufsatz eines „Marterls“ besitzt in der Regel eine oder mehrere tabernakelförmige Öffnungen, die ein Bild bzw. Bilder enthalten können - zunächst dem Begriff „Marterl“ entsprechend Bilder der Passion Christi, die ab dem 18. Jh. dann zunehmend durch Marienbilder ersetzt werden. ${ }^{48}$ Analog Votivtafeln kann zur Ikonographie des Marterls eine Abbildung des Unglücksfalls gehören.

Es ist nicht ungewöhnlich dass Grabmäler die Form von Bildstöcken bzw. die der funktionsgeschichtlich verwandten „Marterln“ aufweisen..$^{49}$ Ein signifikantes und angesichts der Bedeutung des Verstorbenen prominentes Beispiel ist das Grabdenkmal für Joseph Görres auf dem Alten Münchner

\footnotetext{
${ }^{45}$ HEVESI, L.: Österreichische Kunst des 19. Jabrhunderts, Zweiter Teil: 1848-1900. Leipzig 1903, S. 183.

${ }^{46}$ WERNER, P. - WERNER, R.: Vom Marterl bis zum Gipfelkreu: Flurdenkmale in Oberbayern. Berchtesgaden 1991, S. 81; Lexikon der Kunst. Architektur, Bildende Kunst, Angewandte Kunst, Industrieformgestaltung, Kunsttheorie, IV: Kony-Mosa. Leipzig 1992, S. 576.

${ }^{47}$ WERNER - WERNER 1991 (wie Anm. 46), S. 84.

${ }^{48}$ Ibidem, S. 61, Lexikon der Kunst, IV 1992 (wie Anm. 46), S. 576.

${ }^{49}$ Wolfgang Westerhoff erwähnte unter den Grabmälern in Wien und St. Pölten zwei, vermutete aber einen höheren Anteil dieses Grabmalstypus. WESTERHOFF, W.: Bildstöcke
}

Südfriedhof. ${ }^{50}$ Entsprechend der Ikonographie der „Marterln“ seit dem 18. Jh. ist in die übergiebelte Nische die auf der Wolkenbank thronende Muttergottes gemalt, mit dem hl. Paulus und dem knienden Joseph Görres, desen demütige Haltung in der Zuordnung zu Paulus dann doch ganz unbescheiden den Anteil von Görres an der katholischen Renovatio des 19. Jhs. andeutet. Immerhin ordnet sich der Geehrte und Betrauerte der traditionellen mariologischen Ikonographie des „Marterls“ unter. Die übliche Darstellung des Unglücks, die Passionsszene, das Marienbild, ist im „Marterl“ für Anzengruber auf dem Wiener Zentralfriedhof durch ein Bronzemedaillon mit dem Profilbildnis des Verstorbenen ersetzt. Anzengruber nimmt jetzt die doppelte Rolle ein, die im „Marterl“ der tödlich Verunglückte und sein himmlischer Beschützer / seine himmlische Beschützerin innehatten. Unbeschadet seiner literarischen Verdienste hatte Ludwig Anzengruber weder Anrecht auf Sakralität, noch war sein Tod ein Unglücksfall. Trotzdem sakralisierte Wilhelmine von Hillern das Anzengruber-Grabmal als Märtyrergrab, und sie ließ die Trauerfigur auferstehen aus diesem „Grabe des Märtyrers“. ${ }^{51}$ Anzengruber selbst hatte literarisch aktiv Anteil an der Sakralisierung des Künstlers im Denkmal und hatte dabei die MarterlForm seines Grabmal andeutungsweise vorweggenommen. In seiner Schrift des „Studentischen Anastasius-Grün-Komitees“ (1877) schrieb er von den „Bildnisse(n) der Helden und Märtyrer, welche wir als unsere Heiligen an den Straßen und Wegen aufstellen $(\ldots))^{\text {“c52 }}$

in Wien. St. Pölten / Wien 1993, S. 12 f. Genauere statistische Angaben bei Haubold 1990 (wie Anm. 34), S. 82. Anton Geitner empfahl 1921 dann neben der Verwendung einheimischer Gesteine die „Form des Bildstöckchens“ als „,(a)echt deutsch (...) unser Gemüt anheimelnd". GEITNER, A.: Das christliche Grabmal (1921). München 1922, S. 49.

${ }^{50}$ LANGHEITER, A. - LAUTER, W.: Der Alte Südfriedhof in München. München 2008, S. 112 ff.

${ }^{51}$ HILLERN, W. VON: Eine Anzengruber-Aufführung in Oberammergau. In: Gedenkblätter an Ludwig Anzengruber. Zusammengestellt als Erinnerung an den 25. Todestag des großen Volksdichters. Ed.: BÖHM, F. J. Breslau 1915, S. 115-119, hier S. 119.

${ }^{52}$ Zit. n. KAPNER, G.: Ringstraßendenkmäler. Zur Geschicbte der Ringstraßendenkmäler. Dokumentation (= WAGNER-RIEGER, 
Tief bewegt ist die in bäuerliche Tracht gekleidete junge Frau an das „Marterl“ herangetreten, berührt es mit der linken Hand, so als ob sie den Stein umarmen wolle, während die rechte als Ausdruck schmerzlichster Trauer die Stirn bedeckt. Das rechte Bein ist angewinkelt - weil sie im Herbeieilen gezeigt ist, oder, wie Weddigen es sehen wollte, weil sie „von Schmerz überwältigt am Fuße des Bildstocks in die Knie gesunken ist" ${ }^{" 53}$ (Vermutlich auch, weil Henri Chapus ,Jeunesse“ das rechte Bein anwinkelt.) Von den zeitnah zum Tod des Dichters publizierenden Autoren begnügte sich Jakob Julius Davids Biographie (1904) mit der Charakterisierung als „frisches Dirnchen" “. ${ }^{54}$ Otto Weddigen (1904) legte sich fest: die junge Frau stelle Anna Birkmeier dar, die weibliche Hauptfigur aus Anzengrubers "Pfarrer von Kirchfeld". ${ }^{55}$ Außer acht lassen darf man wohl, angesichts des späten Erscheinungsdatums 1929, die von Josef Soyka im Katalog der Gedächtnisausstellung für Hans Scherpe im Wiener Künstlerhaus erfolgte Identifikation dieser „Mädchenblüte vom Berghang“ mit der „Horlacher Lies“ aus Anzengrubers „G'wissenwurm“. ${ }^{56}$ Anton Bettelheim, der als Freund des Verstorbenen, als einer der Initiatoren und maßgebliches Mitglied des AnzengruberKuratoriums, als Biograph Anzengrubers, die weitreichendste Kompetenz beanspruchen darf, ließ dem Betrachter die Wahl zwischen Anna Birkmeier und Magdalena Reindorfer: „Ein Bauernmädchen, das man getrost als Doppelgängerin der Anna Birkmeier oder der Magdalen' Reindorfer ansehen mag, erfährt unterwegs jählings durch ein ,Marterl' den Heimgang des Dichter(sic) und klammert sich

R. (Hrsg.): Die Wiener Ringstraße. Bild einer Epoche. Die Entwicklung der inneren Stadt Wien unter Kaiser Franz Joseph, IX, Plastik, 1). Wiesbaden 1973, S. 130.

${ }^{53}$ WEDDIGEN, O.: Die Rubestätten und Denkmäler unserer deutschen Dichter. Halle 1904, S. 3. Einen Überblick über Trauerfiguren an Grabmälern in Wien und Niederösterreich gibt: KITLITSCHKA, W.: Grabkult \& Grabskulptur in Wien und Niederösterreich. St. Pölten - Wien 1987, S. 79 ff.

${ }^{54}$ DAVID, J. J.: Anæengruber. Leipzig 1904, S. 72. Ähnlich Ottokar Kernstock 1915: „,echte waldfrische Hochlandsdirn“. KERNSTOCK, O.: Meister Ludwig. In: BÖHM, F. J. (Hrsg.): Gedenkblätter an Ludwig Anzengruber. Zusammengestellt als Erinnerung an den 25. Todestag des großen Volksdichters. Breslau 1915, S. 113-114, hier S. 114. laut aufschluchzend an den Pfahl des Bildstockes, dessen Votivbild porträttreu die Züge Anzengrubers vergegenwärtigt. ${ }^{\text {“57 }}$

Darüber zu diskutieren, welche von den genannten Frauengestalten der Werke Anzengrubers sich im Grabdenkmal Scherpes spiegelt, scheint müßig, da in jedem Fall die Trauernde für das literarische Werk Anzengrubers im Ganzen steht. Albert Hofmann, in seinem Band über „Denkmäler mit architektonischem oder vorwiegend architektonischem Grundgedanken“ (1906), den er im Rahmen des "Handbuchs der Architektur" publizierte, erkannte in dem ,trauernden Bauernmädchen“ eine „Verkörperung der Volkspoesie“. ${ }^{58}$ Für den Anzengruber auch persönlich verbundenen Schauspieler Rudolf Tyrolt hatte Scherpe „das Volk verkörpert in der Gestalt eines Bauerndirndls" ${ }^{59}$ Vergleichbar zu Repräsentanten der Ikonographie des Künstlers verallgemeinert reichen, wie gesehen, im Denkmal für Jean-François Millet im Park von CherbourgOcteville (1892) die junge Bäuerin und ihre kleine Tochter Blumen des Feldes hoch zur Büste des Geehrten; vergleichbar streut im Grabmal für den Maler Augustin Feyen-Perrin unter der Büste des Verstorbenen die bretonische Fischerin („La Cancalaise") stellvertretend für das bevorzugte Bildpersonal des verstorbenen Künstlers Blumen auf die Grablege. Man darf nicht ausschließen, dass Scherpe diese, zumindest eines dieser im Vorjahr vollendeten Werke kannte, doch sein Modell lag bereits 1890 vor, sodass von Abhängigkeit keine Rede sein kann. Bemerkenswert immerhin, dass die Verwandlung einer Muse, resp. einer Personifikation in eine das künstlerische

${ }^{55}$ WEDDIGEN 1904 (wie Anm. 53), S. 3.

${ }^{56}$ SOYKA, J:: Hans Scherpe 1853-1929. In: Gedächtnisausstellung Hans Canon und Hans Scherpe, Katalog der Ausstellung. Wien, Künstlerhaus 1929. Wien 1929, S. 27-32, hier S. 28.

${ }^{57}$ BETTELHEIM 1893 (wie Anm. 42), o. S., BETTELHEIM 1898 (wie Anm. 40), S. 285.

${ }^{58}$ HOFMANN, A.: Denkmäler. II. Denkmäler mit architektonischem oder vorwiegend architektonischem Grundgedanken (= Handbuch der Architektur, 4. Teil, 8. Halbband, Heft 2b). Stuttgart 1906, S. 444.

${ }^{59}$ TYROLT 1915 (wie Anm. 41), S. 74. 
Schaffen des Geehrten/Verstorbenen resümierende Frau aus dem einfachen Volk annähernd zeitgleich in Paris und Wien erfolgte.

Keine dieser in volkstümlichen Gestalten Verkörperten trauert freilich so expressiv wie Scherpes „frisches Dirnchen“. Scherpes Trauernde erscheint untröstlich in ihrem Schmerz. Insofern ist die Frage doch berechtigt, zu welcher Identifikation Scherpe - unbeschadet dem bleibenden Anspruch, das „volkstümliche“ Oeuvre Anzengrubers insgesamt zu repräsentieren - den Besucher des AnzengruberGrabmals geneigter machte. Hinsichtlich dieser Frage ist, da Anzengrubers Werke so präsent nicht mehr sind, eine kurze Inhaltsangabe des von Bettelheim genannten Bühnenstücks und des Romans geboten.

Der „Pfarrer von Kirchfeld“"60 ist, worauf sein Nachname bereits verweist, der aufgeklärte Geistliche Peter Hell, eine Identifkationsfigur des Autors in seiner Positionierung gegen den reaktionären Ultramontanismus und für einen liberalen, aufgeklärten Katholizismus. Diese von Pfarrer Hell vertretene kirchenpolitische Haltung bringt ihn in Konflikt mit seinem vormaligen adeligen Förderer, der die Suspendierung Hells von der Pfarrstelle in Kirchfeld und seine Exkommunikation betreibt. Das gute Verhältnis Hells zu seinen Pfarrkindern - mit Ausnahme des aufgrund persönlicher Kränkung zum Kirchenfeind gewordenen „Wurzelsepp“ - droht zu brechen, nachdem der „Wurzelsepp“ den Verdacht streute, der Priester unterhalte eine Liebesbeziehung mit seiner Haushälterin, der jungen schönen Anna Birkmeier, die ihm sein Pfarrerskollege aus einem Nachbarort ans Herz gelegt hatte. Tatsächlich, wengleich nur insgeheim, hatte sich Hell in Anna verliebt. Diese nimmt, nachdem die Gemeinde sich von dem vormals verehrten Pfarrer abzukehren droht, den Eheantrag eines jungen Bauern aus ihrem Heimatdorf an; beide bitten Hell, die Trauung zu vollziehen, was dieser - nach anfänglichen Seelenqualen und

\footnotetext{
${ }^{60}$ ANZENGRUBER, L.: Der Pfarrer von Kirchfeld. In: ANZENGRUBER L.: Anzengrubers Werke, 1. Teil. Ed.: BETTELHEIM, A. Berlin - Leipzig - Wien - Stuttgart 1920, S 25-82.

${ }^{61}$ Eine der Funktion des Textes angemessen ausführliche Inhaltsangabe liefert der von Bettelheim publizierte Zensurbericht der Wiener Polizei: BETTELHEIM, A.: Einleitung. In: AN-
}

der Hoffnung, Anna werde noch am Traualtar das Ja-Wort verweigern - auch tut. In den Augen der Gemeinde ist Pfarrer Hell daraufhin rehabilitiert, doch seiner Suspendierung kann er sich nicht entziehen. ${ }^{61}$

Mit der Nennung von Magdalena Reindorfer brachte Bettelheim den ersten Roman Anzengrubers ins Spiel: Die weibliche Heldin in „Der Schandfleck“, Magdalena Reindorfer, wurde als Frucht eines Seitensprungs der Bäuerin im Hause Reindorfer geboren und vom Bauern zunächst nur aus Sorge vor Schande als leibliche Tochter aufgezogen. Als Magdalena sich in den Müllerssohn Florian verliebt, muss die Wahrheit ans Licht: Florians Vater ist der uneheliche Vater Magdalenas. Magdalena verlässt daraufhin den Reindorferschen Bauernhof und nimmt in einem Nachbardorf eine Bedienstetenstelle an. Das Ende des Romans - Anzengruber sah sich genötigt, für die erste Publikation einen anderen als den geplanten Schluss zu konzipieren, was er auf Drängen des Freundes und Förderers Wilhelm Bolin später korrigierte $^{62}$ - beschreibt das Leid des alten Bauern, der, von seiner Schwiegertochter gedemütigt, den Hof verlässt, von seiner ältesten Tochter abgewiesen wird, um schließlich beim „Schandfleck“" Magdalena und ihrem Gatten vergleichbar dem Shakespearschen König Lear liebevolle Aufnahme zu finden. ${ }^{63}$

Beide Werke markieren für Anzengrubers literarische Laufbahn wichtige Schaltstellen. Mit seinem Romandebüt, „Der Schandfleck“", antwortete Anzengruber auf die zeitweilige Flaute in der Gunst des Wiener Theaterpublikums für seine Bühnenstücke. ${ }^{64}$ Existenziellere Bedeutung hatte „Der Pfarrer von Kirchfeld" für die Biographie des Autors. Als gescheiterter Schauspieler, gegen seine Begabung und Neigung im Polizeidienst tätig, wagte es Anzengruber nicht, das Manuskript unter seinem Namen dem Mitdirektor des Theaters an der Wien zukommen zu lassen. Die Lektüre überzeugte Maximilian Steiner: „Ich habe den Mann gefunden, den ich suche, der

ZENGRUBER 1920 (wie Anm. 60), S. 13-22, hier S. 14 ff.

${ }^{62}$ FRIEDMANN, S.: Ludwig Anzengruber. Leipzig 1902, S. 145 f.

${ }^{63}$ Die Zusammenfassung unter Zuhilfenahme von FRIEDMANN 1902 (wie Anm. 62), S. 145 ff.

${ }^{64}$ FRIEDMANN 1902 (wie Anm. 62), S. 145. 
Reformator der Volksbühne ist da (...). ${ }^{، 65}$ Die Uraufführung am 5 . November 1870 war ein enormer Erfolg und machte den Autor, nachdem er sich als solcher kenntlich gemacht hatte, sofort zum neuen Stern am Wiener Theaterhimmel. ${ }^{66}$ Am Abend nach der Beerdigung Anzengrubers wurde denn auch, wie bereits notiert, „Der Pfarrer von Kirchfeld“ im Volkstheater gespielt. ${ }^{67}$ Daneben spricht ein Detail dafür, dass das „Bauernmädchen“ am Grabmal doch eher als „Doppelgängerin der Anna Birkmeier“ konzipiert wurde. Um die Hand der Trauernden, die an den Grabstein greift, ist ein Rosenkranz gewickelt. Fromm ist gewiss auch Magdalena Reindorfer, doch eine inhaltlich tragende Rolle spielt Religiosität im „Pfarrer von Kirchfeld“ mit seiner kirchenpolitisch aufklärerischen und zölibatkritischen Aussage.

Wenn man also bereit ist, neben der Wahrnehmung der bäuerlichen Figur am Grabmal als allgemeine Personifikation des „volkstümlichen“ Schaffens Anzengrubers die Konkretisierung dieser ,Allegorie' als Anna Birkmeier zu bevorzugen, dann hat das Konsequenzen für den Realitätscharakter des Grabmals. Anders als in den vergleichbaren französischen Denk- und Grabmälern ist die Trauer der Anna Birkmeier keine gemessene. So leidenschaftlich wird am Grabmal üblicherweise nicht um den literarischen oder bildkünstlerischen Vater getrauert. Diesbezüglich rückt Scherpes Trauerfigur dann doch wieder näher an die paradigmatische Trauerfigur Henri Chapus in der Pariser „Ecole de Beaux-Arts“. Trauer und der Appell an ein neues, junges Frankreich werden in der Allegorie der „Jugend“ sinnfällig; sie werden sinnfällig gemacht über die ausgesprochen erotische Beziehung, in die die Trauerfigur zur Büste des Gefallenen tritt. Der „Jugend“ am Denkmal Regnaults hat das von der linken Schulter geglittene Kleid den Rücken entblößt und die linke Brust freigelegt, und unter dem enganliegenden Stoff zeichnen sich die Gesäßbacken deutlich ab. ${ }^{68}$ Mit der von Chapu intendierten oder in der Rezeption erfolgten Überblendung der Allegorie mit

\footnotetext{
${ }^{65}$ BETTELHEIM 1920 (wie Anm. 61), S. 13 f.

${ }^{66}$ Ibidem, S. 13.

${ }^{67}$ TYROLT 1915 (wie Anm. 41), S. 74.
}

der um den Verlobten trauernden Geneviève Breton konkretisierte sich die Trauer der jungen Nation über den Tod des Helden in der individuellen Trauer einer Liebenden.

In eben diesem Sinne stellt sich auch vor dem Anzengruber-Grabmal der Eindruck ein, dass in die Trauer der literarischen Figur um den Autor die Trauer über den Verlust einer geliebten Person hineinspielt. Die unausgesprochene Liebe des Priesters Hell wird unausgesprochen erwidert. Anna rechtfertigt ihren Ehewunsch mit der Treue zum Priester, dem sie so am besten dienen, will heißen: die Verdächtigungen aus der Welt schaffen könne. Doch dürfe das kein vergebliches Opfer sein, „,(d)enn sonst, mein' Seel, sonst lasset ich's gleichwohl sein, wann's für nix sein sollt, auch haltet treu bei dir aus bis ans End'“" Dieser Ausbruch an Leidenschaft (Regieanweisung: „Ausbrechend“) verstört den Verlobten (Regieanweisung: ,stupft sie erschreckt mit den Ellbogen"). ${ }^{69}$ In der Legierung der Trauer über den verlorenen Geliebten im Bühnenstück mit der Trauer um Anzengruber lädt sich am Grabmal letztere erotisch auf. Der „Festgruß“ anlässlich der Enthüllung des Grabdenkmals, formuliert von dem, was Volkstümlichkeit anbelangt, verwandten Peter Rossegger, liefert für den erotischen Bezug von Werk und Schöpfer zumindest Andeutungen: „Zu diesem Bild (das Porträtmedaillon, HK) des Volkes Seele blickt in Lust und Schauern; / Ein Jauchzen hat sie, daß er kam, und daß er ging, ein Trauern. O späte Liebe, die wir anders nimmer stillen können, / Als daß wir, sein gedenkend, diese Weihestätte krönen. ${ }^{\text {“70 }}$

\section{Das Denkmal für Ludwig Anzengruber auf dem Schmerlingplatz in Wien}

In Hinblick auf Strategien der Ehrung von verstorbenen Künstlern verdient auch und besonders das Denkmal Berücksichtigung, das man dem „Reformator der Volksbühne“ 1905 setzte. (Abb. 16) 1898 war

\footnotetext{
${ }^{68}$ Die Passage ist übernommen aus: KÖRNER 2016 (wie Anm. 32), S. $59 \mathrm{f}$.

69 ANZENGRUBER 1920 (wie Anm. 60), S. 67.

${ }^{70}$ Zit. n. BETTELHEIM 1898 (wie Anm. 40), S. 286.
} 


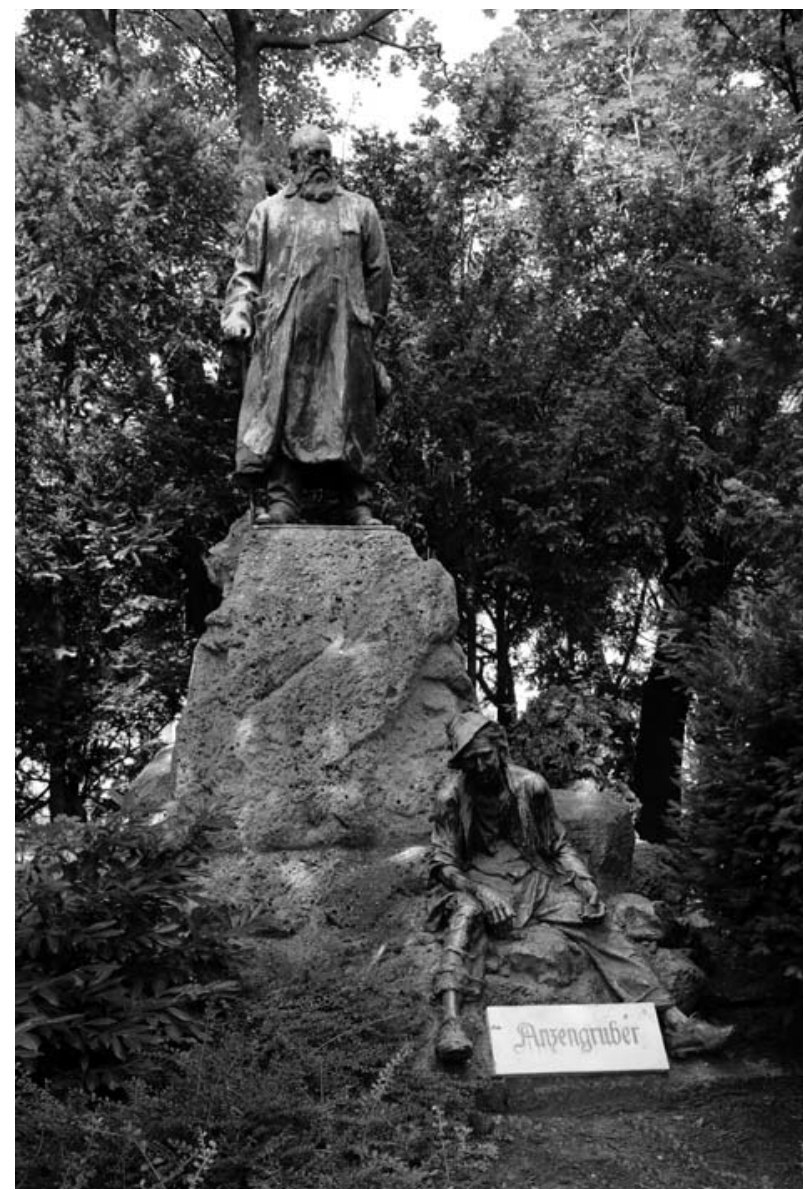

Abb. 16: Scherpe, Hans, Denkmal für Ludwig Anzengruber, 1905, Wien, Schmerlingplatz. (Wikimedia Commons. Foto: Bwag)

der Auftrag unter Verzicht auf einen Wettbewerb an Hans Scherpe vergeben worden. ${ }^{71}$ Bereits der Aufstellungsort ist bemerkenswert. Auf dem Schmerlingplatz, nahe der Ringstraße und doch abgerückt vom Verkehr, wurde das Denkmal in die natürliche Umgebung einbezogen, bzw. diese in Hinblick auf die Wirkung des Denkmals verändert: Der Stadtrat

\footnotetext{
${ }^{71}$ PÖTZL-MALÍKOVÁ, M.: Die Plastike der Ringstraße - Künstlerische Entwicklung 1890 - 1918 (= R. Wagner-Rieger, R. (Hrsg.), Die Wiener Ringstraße. Bild einer Epoche. Die Entwicklung der inneren Stadt Wien unter Kaiser Franz Joseph, Bd. IX, Plastik, 2). Wiesbaden 1976, S. 16.

${ }^{72}$ Zit. n. KAPNER 1973 (wie Anm. 52), S. 46.
}

hatte bestimmt, „daß die Bäume und Gesträuche von der gegen die Ringstraße zugewendeten Spitze der Anlage zu entfernen, hingegen die seitwärts und rückwärts befindlichen Gehölze zu ergänzen sind, daß die unschönen Durchblicke gänzlich verschwinden.“"72 Ein bühnenbildartiger Aufbau wurde auf diese Weise inszeniert, dessen „Hintergrund“ „durch eine Gruppe von Nadelhölzern (...) stimmungsvoll abgeschlossen“" wurde. Aus dem Waldesdunkel, den dieser „Hintergrund“ evoziert, tritt die Denkmalsstatue heraus auf einen „Felsblock(...), von dem sie scheinbar auf den Hang einer Lichtung niedersieht ${ }^{\text {“ }}{ }^{73}$ Die übliche Aufsockelung der Denkmalsfigur ist also in ein Narrativ übersetzt, in eine Szene, die einem Bühnenstück Anzengrubers entnommen sein könnte. Um genau zu sein: Angespielt ist auf „Die Kreuzelschreiber“ (Uraufführung 1872 im Theater an der Wien), das unter kirchenpolitischen Rücksichten brisanteste Stück, das deshalb die Zensurbehörde der Wiener Polizei zum Verbot empfahl, eine Empfehlung, der der dafür Verantwortliche der Statthalterei aber nicht nachkam. ${ }^{74}$

Auslöser der Verwicklungen ist eine Unterschriftenliste gegen das Dogma der Unfehlbarkeit des Papstes, die der Großbauer von Grundldorf im Sinne Ignaz von Döllingers initiierte und wofür er auch die Unterstützung der Bewohner des Nachbardorfes gewann, von denen die Mehrzahl aber als Analphabeten anstelle ihrer Unterschrift ein Kreuz auf die Liste setzen. ${ }^{75}$ Aufgestachelt durch ihren Beichtvater sperren die Frauen des Dorfes, vergleichbar den Frauen Athens und Spartas in der Komödie „Lysistrata“ des Aristophanes, ihre Männer aus den ehelichen Schlafzimmern aus. Der kluge „Steinklopferhans“ bringt die Lösung. Er empfiehlt den Männern des Dorfes zum Schein auf die Forderung ihrer Frauen, eine Sühnewallfahrt nach Rom zu unternehmen, einzugehen. Die Absicht, auf der Wallfahrt einen ,Jungfernbund" mitzunehmen, so wie vormals „d'Markatenderinnen d'Soldaten“ be-

${ }^{73}$ Ibidem, S. 46.

${ }^{74}$ BETTELHEIM 1920 (wie Anm. 61), S. 154, 156

${ }^{75}$ Genutzt wurde auch die Inhaltsangabe in den Zensurakten der Polizeidirektion Wien, publiziert in: BETTELHEIM 1920 (wie Anm. 61), S., 154 ff. 
gleitet hatten, ${ }^{76}$ erregt die Eifersucht der Gattinnen, führt zum Verzicht auf die ohnedies nicht ernsthaft in Betracht gezogene Wallfahrt und stiftet in Zwentdorf wieder eheliche Eintracht.

Der „Steinklopferhans“ ist eine der berühmtesten Bühnenfiguren Anzengrubers geworden. Die schwere Kindheit als uneheliches Kind, die Misshandlungen beim Militär, die ihn zum Krüppel machten, die Armut und die elende Arbeit als Steinklopfer haben ihn nicht verbittert, sondern im Gegenteil zum klugen Verkünder einer optimistischen, weil pantheistischen Weltsicht werden lassen. ${ }^{77}$ Ludwig Anzengruber muss zu dieser seiner Bühnenfigur eine besondere Zuneigung gefasst haben, machte er ihn doch einige Jahre später (1880) zum Mittelpunkt einer Sammlung von Kurzgeschichten („Märchen des Steinklopferhanns"), in denen dieser lebensklug mit Erzählungen Weisheiten unter seine Mitmenschen bringt. ${ }^{78}$ Diese besondere Verbundenheit von Autor und Kunstfigur manifestiert sich in Hans Scherpes Denkmal auf dem Schmerlingplatz: Vom Felsen - der Naturalisierung des Denkmalsockels $^{79}$ - herabblickend beobachtet Anzengruber den „Steinklopferhans" bei der Arbeit im Steinbruch. Der Steinbruch als Handlungsort war am Schmerlingsplatz nachgebildet worden. Sockel, aufgesockelte Denkmalsstatue und die die übliche Allegorie am Postament vertretende Figur wurden in ein lebendes Bild übersetzt. Autor und Werk treten in Beziehung zueinander, vergleichbar dem Grabdenkmal auf dem Zentralfriedhof. Hier nimmt das Kunstwerk Anteil an seinem Autor, dort der Autor an seinem Werk

Mária Pötzl-Malíková machte auf das Vorbild aufmerksam, dem Scherpe bei der Konzeption dieser

\footnotetext{
${ }^{76}$ ANZENGRUBER I 1920 (wie Anm. 60), S. 206.

${ }^{77}$ BETTELHEIM 1920 (wie Anm. 61), S. 157.

${ }^{78}$ ANZENGRUBER, L.: Die Märchen des Steinklopferhanns. München 1922.

${ }^{79}$ Pötzl-Malíková würdigte das Werk als „das bedeutendste Denkmal des Naturalismus im Bereich der Ringstraße“. PÖTZL-MALÍKOVÁ 1976 (wie Anm. 71), S. 17. Zum naturalisierten Denkmalssockel: TRAGATSCHNIG, U:: Sinnbild und Bildsinn. Allegorien in der Kunst um 1900. Berlin 2004, S. 221 f.
}

${ }^{80}$ PÖTZL-MALÍKOVÁ 1976 (wie Anm. 71), S. 17 f.
Figur verpflichtet war: ${ }^{80}$ Achille D’Orsis „Proximus tuus“ "erregte auf der „Esposizione nazionale di Belle Arti“ 1880 in Turin Ausehen und wurde zum Hauptwerk der „Sozialistischen Skulptur“ deklariert. ${ }^{81}$ Aus dem alten Proletarier D'Orsis, der entkräftet seine Hacke niedergelegt hat, machte Scherpe, der D'Orsis Steinklopfer 1894 in Wien sehen konnte, ${ }^{82}$ den während einer Arbeitspause fröhlich seinen Gedanken nachhängenden „Steinklopferhans“. Die Botschaft des Vorbildes (und der wiederum für D'Orsi vorbildhaften Gemälde - Millets Pastell eines erschöpften Weinbergarbeiters und BastienLepages „Heuernte“683) verkehrte Scherpe in seinen optimistisches Gegenpart.

Scherpes Anzengruber-Denkmal ist ein bemerkenswertes Beispiel für die Transformation der üblichen Denkmalsbestandteile - Denkmalsstatue, Sockel, Begleitfigur am Sockel - in eine erzählerische Szene, mit Einbeziehung (und Transformation) des landschaftlichen Ambientes in die Bildwirkung. Der Bildhauer war - der Aufstellungsort stand noch nicht fest - ausdrücklich auch auf „die Ausführung der um das Monument projectierten Gesteine" und die „nöthige Umgestaltung der Gartenanlage“ verpflichtet worden. ${ }^{84}$ Ludwig Hevesi beeindruckte angesichts des Gipsmodells diese ,populäre Genrescene" durchaus, auch, dass „der Platz umher keine obligate Blumenanlage, sondern ein Stück Steinbruchlandschaft mit Kraut und Unkraut und einem Föhrenhain" sein sollte. ${ }^{85}$ Doch befürchtete er, dass das Denkmal am vorgesehenen Aufstellungsort sich „zwischen dem Asphalttrottoir und dem Mörtelputz des Theaters wie ein Stück Salontirol ausnehmen wird.“ Größere Vorbehalte noch hatte Hevesi ge-

\footnotetext{
${ }^{81}$ CASERO, C.: La "scultura sociale" tra il vero e l'ideale. Realismo e impegno della plastica lombarda di fine Ottocento. Verona, 2013, S. 21.

${ }^{82}$ PÖTZL-MALÍKOVÁ 1976 (wie Anm. 71), S. 17.

${ }^{83}$ CASERO 2013 (wie Anm. 81), S. 24.

${ }^{84}$ BETTELHEIM, A. - FELLNER, R.: Das Anzengruber=Denkmal auf dem Schmerling=Platr in Wien. Rechenschaftsbericht. Wien 1905, S. 11.

${ }^{85}$ Zit. n. KAPNER 1973 (wie Anm. 52), S. 206, 208.
} 


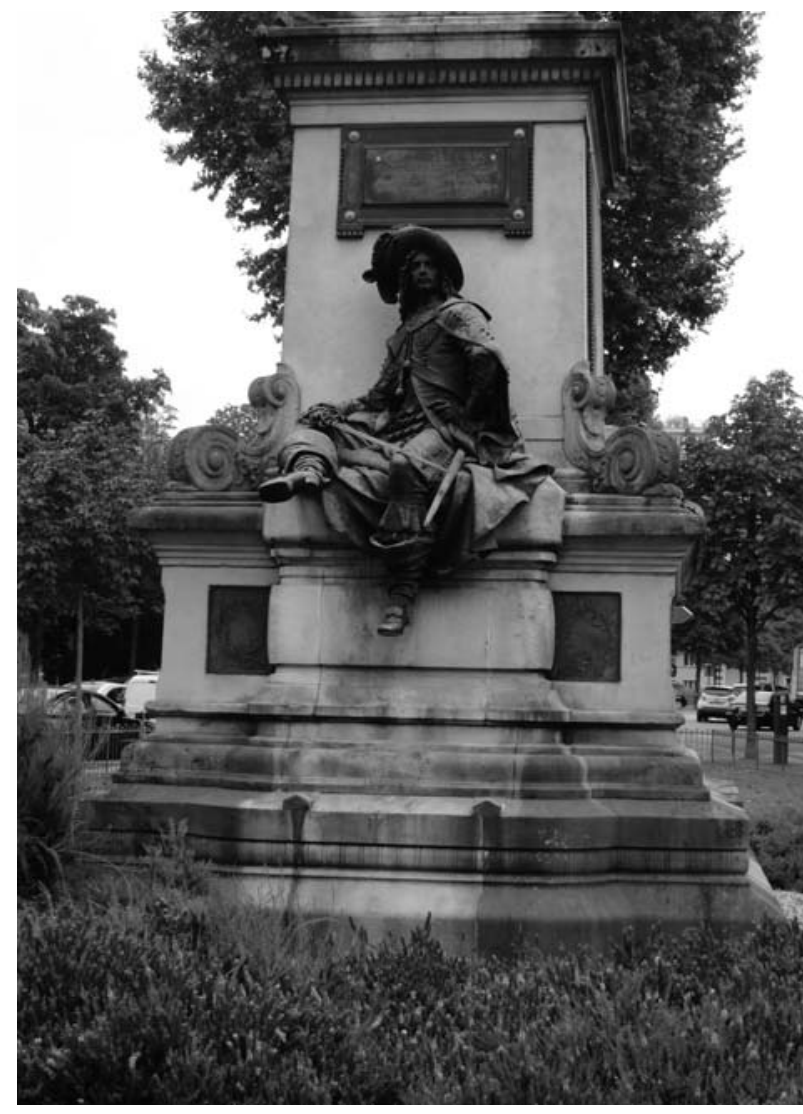

Abb. 17: Doré, Gustave, Bowvard, Joseph-Antoine, Gravigny, Ulysse (Archit.), Denkmal für Alexandre Dumas père (Detail), 1883, Paris, Place du Général Coutreau (Foto: Hans Körner)

gen Scherpes Konzeption des „Steinklopferhans“. Das Gipsmodell erweckte in Hevesi (zu Recht) den Verdacht, dass Scherpe den Schauspieler Martinelli abbilden werde. „Hans Scherpe muss thun, was der Dichter gethan, und sich einen echten Steinklopfer

${ }^{86}$ Zit. n. KAPNER 1973 (wie Anm. 52), S. 208. Zu Hevesis Rezeption des Denkmals: SELBMANN, R.: Dichterdenkmäler in Deutschland. Literaturgeschichte in Erz und Stein. Stuttgart 1988, S. 136.

${ }^{87}$ Tschechische Theaterensyklopädie (http://de.encyklopedie.idu.cz/ index.php/Martinelli_Ludwig (12.10.2019)

${ }^{88}$ BETTELHEIM - FELLNER 1905 (wie Anm. 84), S. 15 f. Beim Begräbnis Anzengrubers hatte Ganghofer bereits das pantheistische Motto des Steinklopferhans vorgetragen. STROBL, K. H.: Ludwig Anzengruber. München 1920, S. 109. aus dem Bergwerk holen, nicht einen falschen aus der Theatergarderobe. ${ }^{\text {“86 }}$

In Hinblick auf die von Scherpe bereits für das Ehrengrab Anzengrubers auf dem Zentralfriedhof herangezogene Strategie der Konkretisierung der beigeordneten Personifikation in ein Kunstwerk des zu Ehrenden, war der „falsche“ Steinklopfer aber der richtige gewesen. Der Schauspieler Ludwig Martinelli hatte am Grazer Theater in den Rollen des „Wurzelsepp“ aus Anzengrubers „Pfarrer von Kirchfeld“ und eben als „Steinklopferhans" in den "Kreuzelschreibern" brilliert. ${ }^{87}$ Martinelli war es denn auch, der bei der Einweihungsfeier auf dem Schmerlingplatz das von Rudolf Hawel verfasste Festgedicht vortrug, das unter dem optimistischen Motto des „Steinklopferhans“: „Es kann da nix g'schegn“ stand. ${ }^{88}$ Anzengruber schätzte die schauspielerischen Fähigkeiten Martinellis außerordentlich, beide waren eng befreundet. ${ }^{89}$ Vor Scherpes Darstellung des Arbeiters in der Brechung durch die von Martinelli verkörperte Bühnenfigur sollte dem Betrachter zuerst und zunächst ein Kunstwerk aus der Feder Anzengrubers begegnen, das seinen Schöpfer rühmt. ${ }^{90}$ Die ,populäre Genrescene“ (Hevesi) ist immer noch ein Denkmal, und der Steinklopfer, den der eben aus dem Wald herausgetretene Dichter unter sich auf der Lichtung sieht, bleibt eine ,allégorie réelle“ der Kunst, nur dass Aufsockelung und allegorische Rühmung jetzt mit dieser „populäre(n) Genrescene“ in Spannung geraten, Spannung, die für die Geschichte des Wiener Dichterdenkmals eine bemerkenswerte Innovation darstellte. Defregger hatte nicht Unrecht, als er Scherpes Anzengruberdenkmal aus der Masse der Wiener Denkmäler heraushob: „Das ist famos, das ist originell. Das ist ein Denkmal, wie es Anzengruber selbst recht wäre. ${ }^{\text {(91 }}$

${ }^{89}$ Österreichisches Biographisches Lexikon (http://www.biographien. ac.at/oebl/oebl_M/Martinelli_Ludwig_1832_1913.xml (12. 10. 2019)

${ }^{90}$ Die Anspielung auf Schillers „Glocke“ klingt auch in Anton Bettelheims und Richard Fellners „Rechenschaftsbericht“ an: „Es ist ein Werk, das dem Geist und Gemüth Anzengruber's wahlverwandt ist und selbst seinen Meister am wirksamsten lobt.“ BETTELHEIM - FELLNER 1905 (wie Anm. 84), S. 19.

${ }^{91}$ Zit. n. SOYKA 1929 (wie Anm. 56), S. 29. 
Wie für das Grabdenkmal auf dem Zentralfriedhof sind, was die Kombination von Kunstwerk und Künstler im Denkmal anbelangt, auch für das Anzengruber-Denkmal auf dem Schmerlingplatz zuerst und zunächst französische Vorraussetzungen bzw. Analogien zu nennen. In Zusammenarbeit mit dem Bildhauer Joseph-Antoine Bouvard und dem Architekten Ulysse Gravigny hatte Gustave Doré das Denkmal für den älteren Alexandre Dumas (Einweihung 1883) geschaffen. Unterhalb der hoch aufgesockelten Sitzfigur des Romanciers lesen Geschwister aus einem Roman des im Denkmal Geehrten. Ein dabei sitzender Arbeiter blickt, da leseunkundig, nicht in das Buch, sondern lässt sich vorlesen. Die Konkretisierung der traditionellen Allegorie am Denkmal erfolgt hier über die Rezeption eines Textes, und in der Verbindung mit dem Analphabeten wird die schichtenübergreifende Popularität der Romane Dumas' veranschaulicht. Rückseitig sitzt D'Artagnon, die wohl populärste Romanfigur Alexandre Dumas d. Ä., am Sockel mit gezücktem Säbel und aufmerksam spähend. (Abb. 17) Als Kunstfigur erweist er seinem Schöpfer die Reverenz und beschützt ihn. ${ }^{92}$ Den Maler und Graphiker Denis-Auguste-Marie Raffet ehrte man 1893 mit einem während der nationalsozialistischen Besatzung von Paris auf Anordnung der VichyRegierung zerstörten Denkmal (ehemals vor dem Louvre). (Abb. 18) Unterhalb der Marmorbüste des Künstlers, stürmte ein (bronzener) Trommler den Sockel entlang. Er ist einer Lithographie Raffets entnommen, auf der der über das Schlachtfeld eilende Trommler die getöteten französischen Soldaten des Kriegs von 1870/71 zu neuem Leben und zur Revanche erweckt. ${ }^{93}$ Ganz aus Nachbildungen von Werken des im Denkmal Gefeierten - vom Bildnismedaillon abgesehen - setzt sich das Denkmal für Antoine Barye zusammen. Laurent Marqueste

\footnotetext{
${ }^{92}$ CLARETIE, J.: Discours. In: Le Monument de Alexandre Dumas, oeuvre de Gustave Doré (...). Paris 1884, S. 9-16, hier S. 16; SANTORIUS, N.: Augenhöhe außer Sichtweite. Aufstellungskonzepte französischer Skulptur im 19. Jahrhundert. In: Der Sockel in der Skulptur des 19. \& 20. Jahrbunderts. Eds.: MYSSOK, J. - REUTER, R. (= Studien zur Kunst 30). Köln - Weimar - Wien 2013, S. 23-39, hier S. 33.

${ }^{93}$ BRESC-BAUTIER, G. - PINGEOT, A.: Sculptures des jardins
}

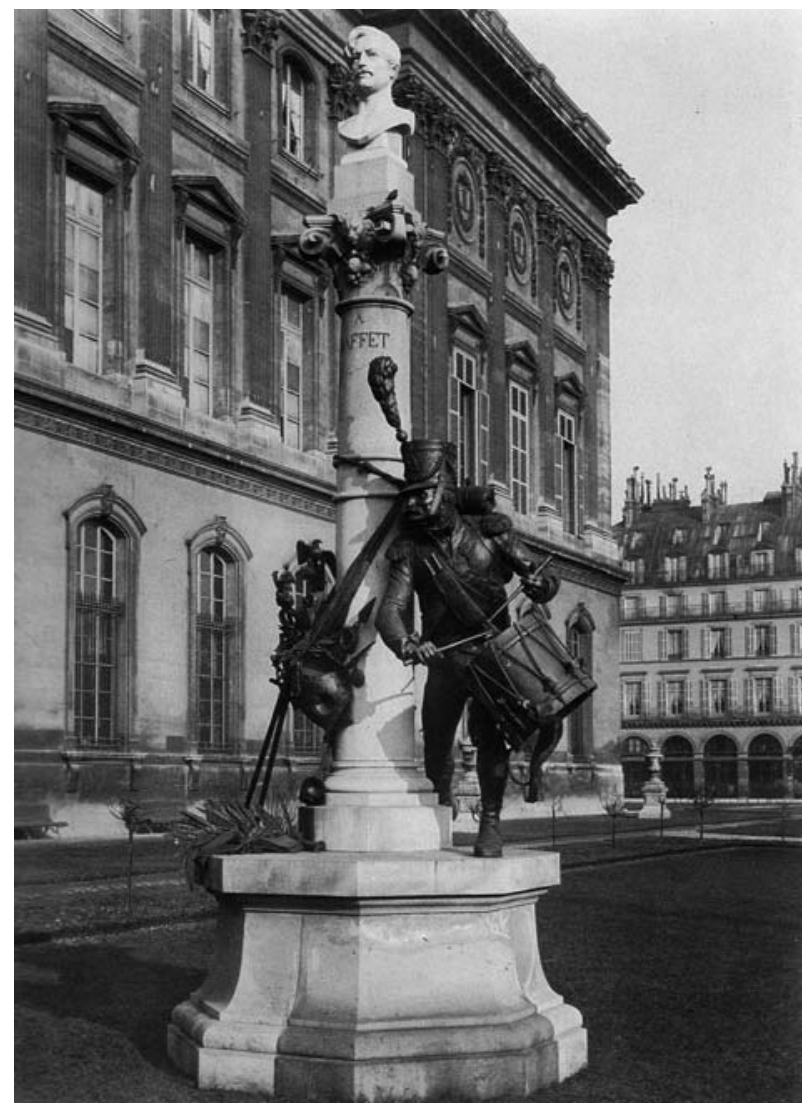

Abb. 18: Frémiet, Emmanuel, Denkmal für Denis-Auguste-Marie Raffet, 1893 (zerstört), ehem. Paris, vor dem Louvre (Bildzitat: Hargrove, June, The Statues of Paris, Antwerpen 1989, S. 149)

kopierte Baryes Allegorien der „Ordnung“ und der „Kraft", die ihre allegorische Semantik jetzt mit der Bedeutung als Kunstwerke Baryes teilen, und er kopierte Baryes „Kampf des Theseus mit dem Kentaur" für die das Denkmal (1894 Enthüllung) bekrönende Gruppe. ${ }^{94}$ Es müssen nicht notwendig nur menschliche Akteure sein, wenn Künstler und

$d u$ Louvre, du Carrousel et des Tuileries, II (= Notes et documents des Musées de France 12). Paris 1986, S. 204; HARGROVE, J.: Les Statues de Paris. Paris 1989, S. 147.

${ }^{94}$ Dazu: SCHMIDT, K. E.: Französische Skulptur und Architektur des 19. Jabrhunderts. Leipzig 1904, S. 25; BARBILLON, C.: Le sculpteur et sa sculpture ... sculptée. In: La sculpture au XIXe siècle. Mélanges pour Anne Pingeot. Paris 2008, S. 378-385, hier S. 383, https:// fr.wikipedia.org/wiki/Square_Barye (28.3. 2020). 


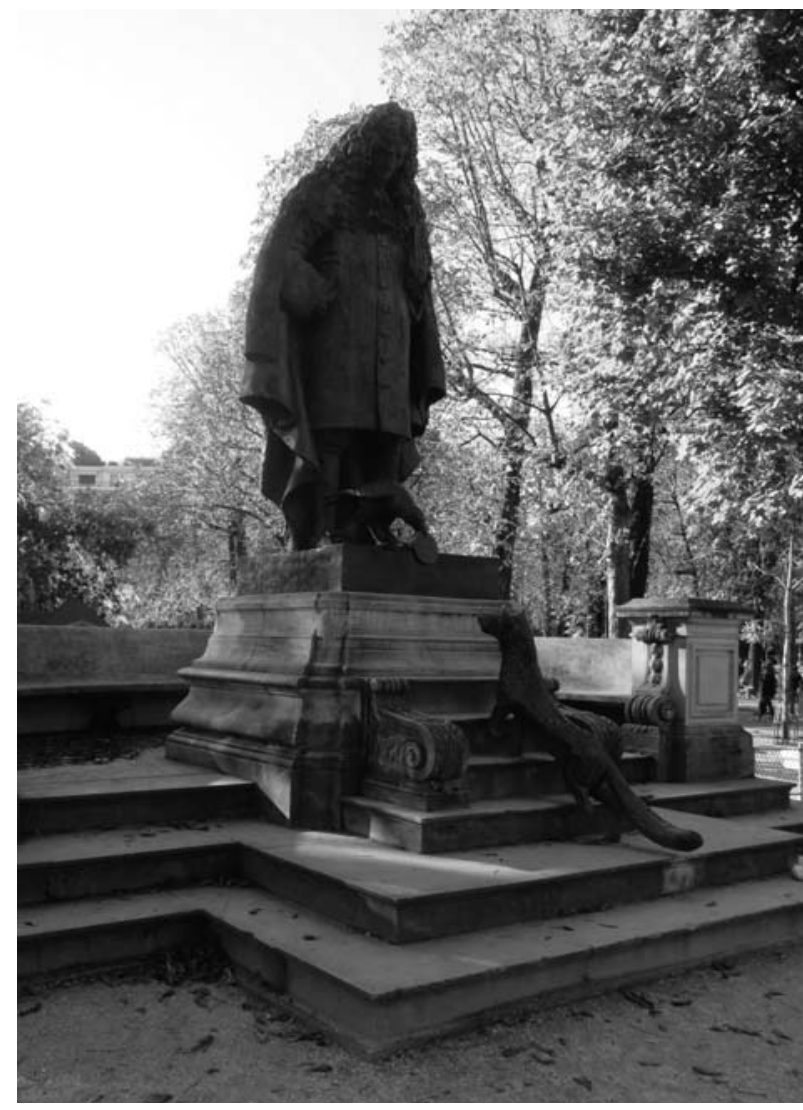

Abb. 19: Dumilatre, Alphonse, Denkemal für Jean de la Fontaine, 1891, Paris, Jardin de Ranelagh (Foto: Hans Körner)

Kunstwerk sich im Denkmal begegnen. Alphonse Dumilâtre ließ im Denkmal für Jean de la Fontaine im Pariser Jardin de Ranelagh den Autor der Fabel von „Le Corbeau et le Renard“ sich und den Raben zu seinen Füßen zum Fuchs herunterbeugen. (Abb. 19)

\footnotetext{
${ }^{95}$ REICHARDT, G.: Heroen der Kunst. Standbilder und Denkmale für bildende Künstler im 19. Jahrbundert. Köln 2009, S. 34; DENK, C.: Der Campo Santo Ludwigs I. in München als neues Pantheon: Die Künstlergrabmäler von Gärtner, Schwanthaler und Klenze. In: Künstlergrabmäler. Genese - Typologie - Intention - Metamorphose. Eds.: MÜNCH, B. U. - HERZOG, M. - TACKE, A. Petersberg 2011, S. 218-244, hier S. 226.

${ }^{96}$ Zit. n. REICHARDT 2009 (wie Anm. 95), S. 129.

${ }^{97}$ Ibidem, S. 129.
}

Im deutschsprachigen Raum kommt das Künstlerdenkmal verspätet. Das von Ludwig I. promovierte Dürerdenkmal für Nürnberg (1828-40) steht am Anfang. ${ }^{95}$ Immerhin wären bereits in diesem Denkmal entsprechend Christian Daniel Rauchs erstem Entwurf auf einem „Cipus (...) seine (Dürers) vorzüglichsten Kunstwerke in verschiedenen Kunstzweigen " abgebildet gewesen. ${ }^{96}$ Diese im Denkmalsganzen allerdings eher untergeordneten Reliefnachbildungen von Kunstwerken wurde nicht ausgeführt; das Projekt wurde verworfen. ${ }^{97}$ Spätere realisierte Verweise auf die Kunst des Künstlers am Denkmal im deutschsprachigen Raum stehen in der Regel allegorisch für vom aufgesockelten Künstler bevorzugten Gattungen der Literatur / Malerei / Musik und blieben vorerst im Medium des Reliefs.

Der Wechsel zur Vollplastik verschaffte den Allegorien gesteigerten Wirklichkeitsanspruch. Ehrungen für Schiller lieferten die ersten Beispiele: Drama, Lyrik, Geschichte und Philosophie sind ihm sowohl im Hamburger (1866) als auch im Berliner Denkmal (1871), in Gestalt von vier Musen bzw. vier Personifikationen beigegeben. Am Gendarmenmarkt sind die Personifikationen überlebensgroß geraten. ${ }^{98}$ Die Präsenz dieser Figuren fiel zeitnahen Autoren auf und hat sogar beunruhigt: Sie seien keine Allegorien mehr, sondern lebendige Wesen, schrieb Berthold Daun in seiner „Kunst des 19. Jahrhunderts und der Gegenwart“ (1909), und er merkte kritisch an, dass diese derart prominent hervorgehobenen Beifiguren das Interesse von der Hauptsache, Schiller, abzögen. ${ }^{99}$ Ziehen gab sich geradezu erschreckt angesichts „dieser Riesenweiber“, die ihn an die antiken „Erinnyen“ gemahnten, und stellte ebenfalls die Frage, ob man solche Figuren noch als Allegorien bezeichnen dürfe. ${ }^{100}$

${ }^{98}$ BECKMANN, U.: Künstlerstandbilder des 19. und beginnenden 20. Jabrbunderts in Deutschland. Kiel 1994, S. 185 f.

${ }^{99}$ DAUN, B.: Die Kunst des 19. Jabrbunderts und der Gegenwart. Ein Grundriß der modernen Plastik und Malerei. Berlin 1909, S. 531 f. Vgl. RUSCHE, A.: Der Sockel. Typologische und ikonographische Studien am Beispiel von Personendenkmälern der Berliner Bildhauerschule (= Beiträge zur Kunstgeschichte, Bd. 1). Bonn 1989, S. 111

${ }^{100}$ Zit. n. BECKMANN 1994 (wie Anm. 98), S. 186. 
Ging im Künstlerdenkmal die Anspielung auf bestimmte Kunstwerke des geehrten Künstlers, dann gebrochen im Puttenspiel (am 1892 enthüllten Denkmal für Mendelssohn-Bartholdy in Leipzig spielen und singen Putten die „HebridenOuvertüre“ und das Volkslied „Es ist bestimmt in Gottes Rat ${ }^{\text {“(101) }}$, oder sie sind zurückgenommen in die Bildfläche des Reliefs, wie die auf Werke Goethe verweisenden Bilder an Ludwig von Schwanthalers Frankfurter Goethe-Denkmal. ${ }^{102}$ (Abb. 20) In Wien ist das bedeutendste Beispiel für die Ausstattung eines Dichterdenkmals mit im Relief nachgebildeten Szenen das 1889 eingeweihte Denkmal für Franz Grillparzer im Volksgarten, deren Auswahl allerdings umstritten war. ${ }^{103}$ Bereits, dass die von Rudolf Weyr geschaffenen Reliefs nicht untergeordnet am Sockel verortet sind, sondern großformatig die einschwingende Exedra füllen, verschaffte ihnen gesteigerte Prominenz. Ausdrücklich war im übrigen die örtliche Nähe des Anzengruber-Denkmals zum Grillparzer-Denkmal vorgegeben worden. Auf den „größte(n) Dramatiker des neuen Österreich“ sollte der „Volksdichter" bezogen bleiben. ${ }^{104}$

Auch was die Integration bestimmter Kunstwerke und bestimmter Kunstwerksfiguren anbelangt steigert die Vollplastik den Realitätsanspruch. Gustav Eberleins Denkmal für Richard Wagner in Berlin aktivierte die potentielle Handlungsfähigkeit der vollplastischen Nebenfigur am Denkmal: Nach der Enthüllung im Jahr 1903 sah man am Sockel lebensgroße Figuren aus Opern des Komponisten (Kriemhild, die den toten Siegfried beweint / Tannhäuser / Alberich und eine Rheintochter) neben den auf ausdrücklichen Wunsch des Kaisers Wilhelms II. integrierten Wolfram von Eschenbach. ${ }^{105}$ Letzterer steigt auf die Stufe und wendet sich rühmend dem thronenden Meister zu. Im deutschsprachigen Raum ist insbesondere ein Dichterdenkmal als mögliches Vorbild für Hans Scherpes Anzengruber-Denkmal zu nennen, in dem die Rühmung des Künstlers durch

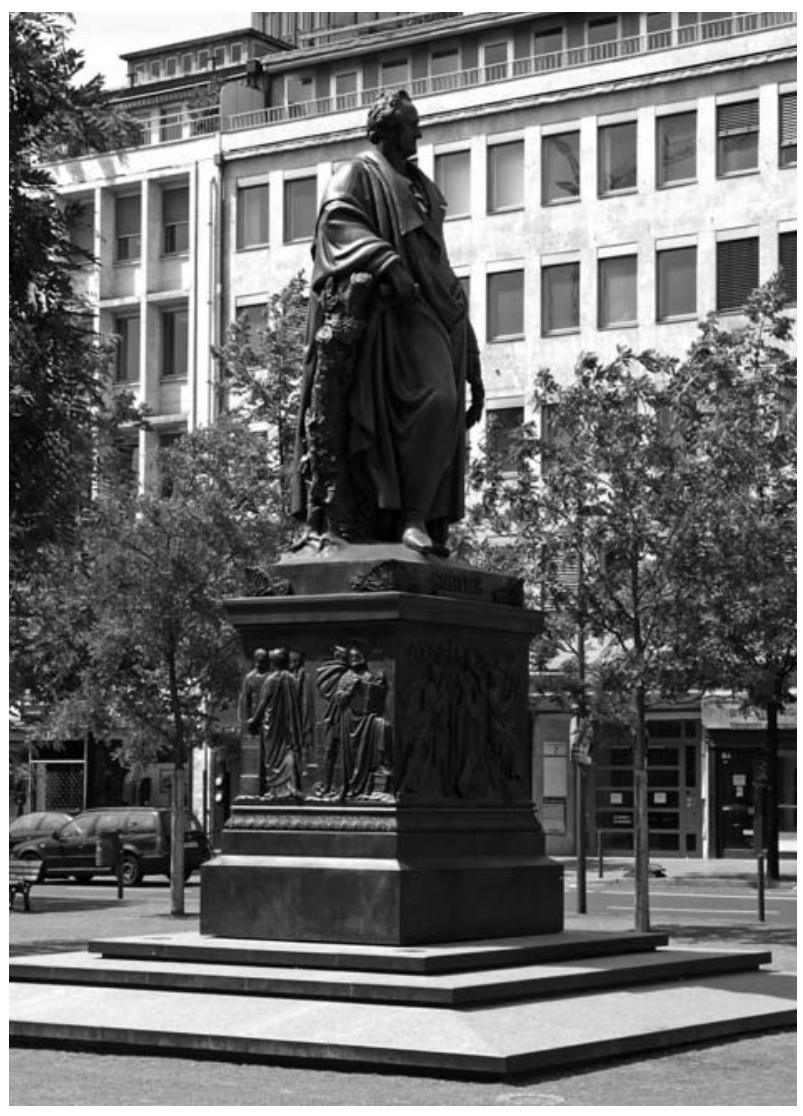

Abb. 20: Schwanthaler, Ludwig von, Denkmal für Johann Wolfgang von Goethe, 1844, Frankfurt, Goetheplatz. (Wikimedia Commons. Foto: Dontworry)

sein Werk sogar ausdrücklich wird. Joseph Victor von Scheffel, dessen Versepos „Der Trompeter von Säkkingen" das spätere Kurbad berühmt gemacht hat, wurde 1901 auf dem Münsterplatz ein Denkmal von Joseph Menges gesetzt. Möglicherweise angeregt von dem Trommler am Sockel des Pariser Denkmals für Raffet trompetete (bevor er 1941 eingeschmolzen wurde) ein Trompeter unterhalb der aufgesockelten Büste Scheffels. In doppelter Weise verweist dieser

\footnotetext{
${ }^{104}$ KAPNER 1973 (wie Anm. 52), S. 46.

105 SELBMANN 1988 (wie Anm. 86), S. 145 f.; RUSCHE 1989 (wie Anm 99), S. 115 f.; BECKMANN 1994 (wie Anm. 89), S. 191.
} 


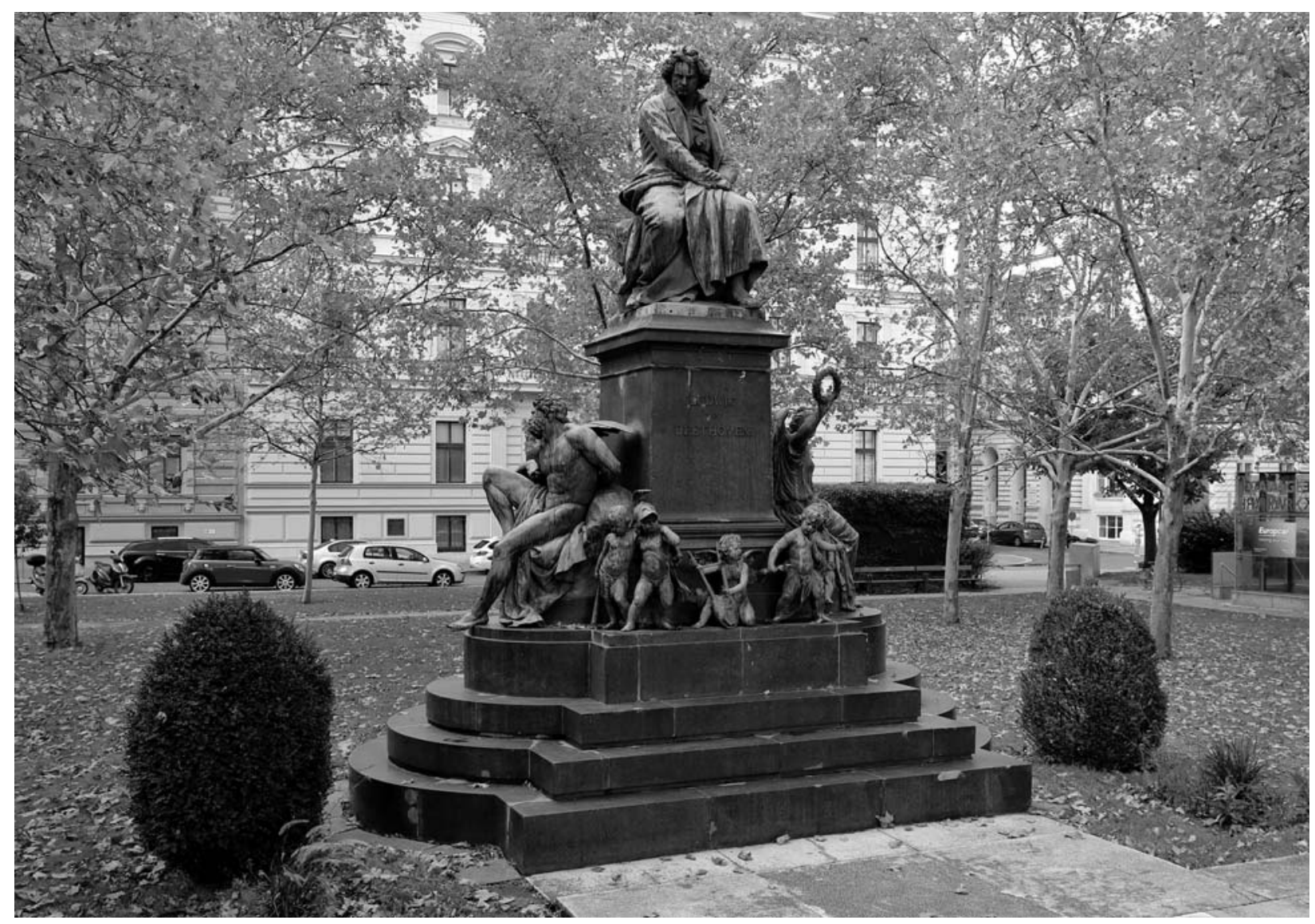

Abb. 21: Zumbusch, Caspar von, Denkmal für Ludwig van Beethoven, 1880, Wien, Beethovenplatz, (Wikimedia Commons. Foto: Bwag)

Trompeter auf Kunstwerke: Er referiert auf die Illustrationen Anton von Werners, und verkörpert selbstverständlich die populäre Figur aus dem Gedicht, zu dem Scheffel die erste Idee um 1850/51 als Rechtspraktikant in Säckingen gekommen war und das er 1853 in Italien abschloss. ${ }^{106}$ Im Denkmal blies der populäre „Trompeter von Säkkingen“ -als „allégorie réelle“ der „Fama“ - den Ruhm seines Dichters in die Welt hinaus.

Sucht man in Wien nach möglichen vollplastischen Voraussetzungen für Beifiguren am Künstlerdenkmal, die als Kunstwerke „den Mei-

\footnotetext{
106 SELBMANN 1988 (wie Anm. 86), S. 113, https://www. trompeter-von-saeckingen.de/scheffel/scheffel.htm (3. 4. 2020).
}

ster loben“, muss vom 1880 enthüllten Beethovendenkmal Caspar von Zumbuschs die Rede sein. (Abb. 21) Der Weg zum Denkmal auf dem Schmerlingplatz ist von daher zwar ein weiter, doch Scherpe konnte hier zumindest Einsichten in die Komplexität der Relation von Allegorie und Kunstwerksikonographie gewinnen. Am Sockel des Beethoven-Denkmals sitzt der angekettete, leidende Prometheus, modelliert in unverkennbarer (auch kritisierter) Anlehnung an den auf dem Gebiet der antiken Skulptur paradigmatischen Dulder Laokoon. ${ }^{107}$ Prometheus meint die eine Seite der

${ }^{107}$ BERGGRUEN, O.: Bildhauerwerke von Zumbusch. In: Die graphischen Künste, VII. Jg., 1885, S. 37-40, hier S. 39 f. 
Kunst Beethovens - die seit E. T. H. Hoffmann sich als „Leidensnotwendigkeit“ zum Topos der Verbindung von Leid und Kreativität und zum allgemeinen Klischee der Musik Beethovens verfestigt hatte, ${ }^{108}$ deren andere Seite - ihr ewigwährender Ruhm - von der Lorbeerkranz weisenden Siegesgöttin verkörpert wird. ${ }^{109}$ Zeitnahe Interpretationen bringen die beiden großen Figuren mit Tragik und Triumph zusammen, die man in dieser Künstlerpersönlichkeit verbunden glaubte. ${ }^{110}$

Zumbuschs Prometheus am Sockel des Wiener Beethoven-Denkmals verweist gleichermaßen auf ein konkretes Werk Beethovens. Hans-Ernst Mittig war nicht überzeugt, dass die neun Putten, die sich zwischen Prometheus und Viktoria am Sockel tummeln, nur Repräsentationen der neun Sinfonien Beethovens seien, auch nicht über die ikonographische Zuweisung der Putten zu den ,verschiedenen Gattungen der von dem Meister gepflegten Musik ${ }^{111}$ Stattdessen: „Meiner Ansicht nach greifen die Kinderpaare zugleich das Prometheus-Thema auf, indem sie durch Haltung und Attribute Szenen des heroisch-allegorischen Ballets „Die Geschöpfe des Prometheus" frei paraphrasieren." 112 Der am Sockel des Wiener Denkmals angekettete Titan, wäre dann auch als Repräsentant eines Beethovenschen Werkes anwesend. Diese Interpretation war bereits unter Zeitgenossen verbreitet: 1881, im Jahr nach der Enthüllung des Denkmals lobte Hugo Blümner den Prometheus am Sockel des Wiener Denkmals als

\footnotetext{
${ }^{108}$ EGGEBRECHT, H. H.: Zur Geschichte der Beethoven-Rezeption. Beethoven 1970. Sonderdruck aus: Akademie der Wissenschaften und der Literatur. Abhandlungen der geistes- und sozialwissenschaftlichen Klasse, Jg. 1972, Nr. 3, 1972, S. 59-138, hier S. 24 ff.
}

${ }^{109}$ Zur Ikonographie des Wiener Beethovendenkmals v. a Miтtig, H.-E.: Das Wiener Beethoven-Denkmal von Zumbusch und die Wende der Beethovendarstellung. In: Kunstchronik, 21. Jg., 1968, S. 403-405, MITTIG, H.-E.: Das Wiener Beethoven-Denkmal von Zumbusch und die Wende der Beethoven-Darstellung. In: Alte und moderne Kunst, 14. Jg., 1969, Nr. 104, S. 25-33.

${ }^{110}$ LÜtzow, Visconti. Siehe MITTIG 1969 (wie Anm. 109), S. 31. BERGGRUEN 1885 (wie Anm. 107), S. 39. Schmoll gen. Eisenwerth schloss sich interpretatorisch der von den Zeitgenossen vorgegebenen Linie an: Versinnbildlicht sei „Kampf, Qual und Meisterschaft des Komponisten“. SCHMOLL GEN. „glückliche(n) Einfall“; die mythische Figur versinnbildliche „wohl die mit einem tragischen Schicksal verbundene titanische Größe des Meisters", erinnere "nebenbei aber auch an eine bedeutende Schöpfung desselben". 113

In jedem Fall gab Zumbusch der ikonographischen Tradition eine bemerkenswerte Wende. Am Denkmalssockel angekettete Figuren bedeuteten in der frühneuzeitlichen Denkmalsttradition Sklaven oder unterworfene Nationen. ${ }^{114}$ Am Denkmal Großherzog Ferdinandos I. in Livorno sind es gefangengesetzte Seeräuber; gefesselte Sklaven kauerten am Sockel des Reiterstandbilds Henrich IV. auf der Pont Neuf in Paris. Auf der Place des Victoires (Paris) erhob sich vor der Französischen Revolution ein Königsdenkmal, unter dem, an die Sockelecken, Figuren angekettet waren - hier als Verkörperungen der vom Geehrten, von Ludwig XIV., unterworfenen Nationen Deutschland, Holland, Osmanisches Reich und Spanien. In der Nachfolge von Desjardins Königsdenkmal auf der Place des Victoires steht die Sockelikonographie des Denkmals für den „Großen Kurfürsten " in Berlin: Als lebende Trophäen sind hier nicht genauer ikonographisch bestimmte Feinde in Ketten gelegt. Mit Zumbuschs Prometheus am Wiener Beethovendenkmal hat die Denkmalsikonographie bei Beibehaltung des Motivs des am Sockel Angeketteten eine radikale Umdeutung erfahren. Er leidet auch, vielleicht vor allem, weil Beethoven nicht mehr unter den Lebenden weilt.

EISENWERTH, J. A.: Zur Geschichte des Beethoven-Denkmals. Sonderdruck aus: Zum 70. Geburtstag von Joseph Müller-Blattau (= Saarbrücker Studien zur Musikwissenschaft, Bd. 1). Kassel - Basel - Paris - London - New York 1966, S. 242-277, hier S. 252.

${ }^{111}$ MITTIG 1969 (wie Anm. 109), S. 32.

112 Ibidem, S. 32. Kürzer in: MITTIG 1968 (wie Anm. 109), S. $404 \mathrm{f}$.

${ }^{113}$ BLÜMNER, H.: Laokoon-Studien. Erstes Heft. Über den Gebrauch der Allegorie in den bildenden Künsten. Freiburg - Tübingen 1881, S. 77.

114 Dazu KÖRNER, H.: Dekorative Fesseln. Die grotesken Satyrn und ibre Nachkommen (= Düsseldorfer Kunsthistorische Schriften, Band 9). Düsseldorf 2009, S. 85 ff. 


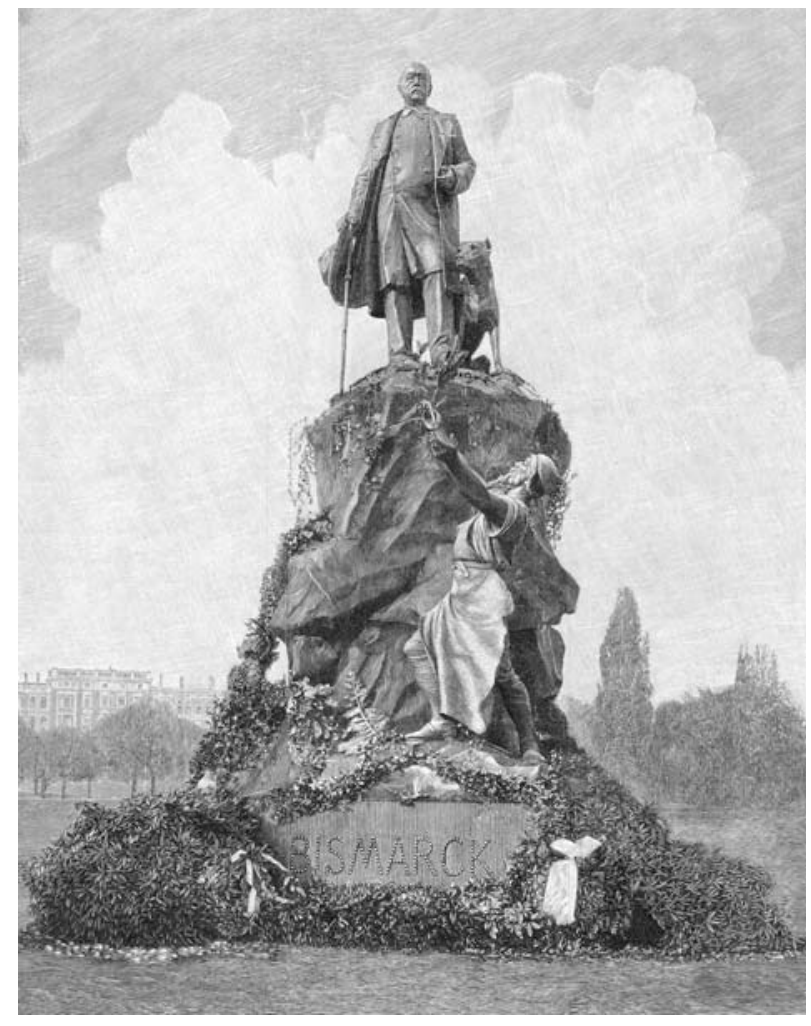

Abb. 22: Lehnert, Adolf / Mágr, Joseph (Schmied), Denkmal für Otto von Bismarck, 1895, Leip rig, zuerst Augustusplat», ab 1897 Johannapark (zerst.) (Stich nach einer Fotografie von Otto Roth. In: Illustrierte Zeitung, 28. Oktober 1897) (Wikimedia Commons)

Hans Scherpe konnte also an eine Tradition anschließen, wenngleich der Traditionspfad nicht sonderlich breit war, und eine ,naturalistische“ Lösung des Problems des den Künstler in seinem Denkmal feiernden Kunstwerks nicht vorlag. Für die Inszenierung mit einem zum Steinbruch umgestalteten Parkbezirk gibt es keine Voraussetzungen. Hans Scherpes Anzengruber-Denkmal war auch

\footnotetext{
$\overline{115}$ https://de.wikipedia.org/wiki/Bismarck-Denkmal_(Leipzig) (4. 4. 2020)

116 Ähnlich auch die Inszenierung in Berlin-Grunewald 1897. EHRHARDT-APOLDA, M.: Bismarck im Denkmal des In-und Auslandes I. Eisenach - Leipzig 1903, Nr. 43.

${ }^{117}$ EHRHARDT-APOLDA, I 1903 (wie Anm. 116), Nr. 66.
}

im europäischen Kontext eine ungewöhnliche und eine ungewöhnlich innovative Lösung. Am ehesten noch wird man in der Inszenierung von BismarckDenkmälern vorbereitende Ansätze beobachten können. 1895 wurde in Leipzig ein BismarckDenkmal zuerst auf dem Augustusplatz eingeweiht, das zwei Jahre später verändert im Johanna-Park aufgestellt wurde. ${ }^{115}$ (Abb. 22) Es zeigt den alten Ruheständler bei seinem Spaziergang im Park des Herrenhauses Friedrichsruh - mit Spazierstock und in Begleitung seines Hundes Tyras. ${ }^{116}$ Die Beschreibung Ehrhardt-Apoldas (1903) macht die intendierte Naturalisierung des Denkmalaufbaus ausdrücklich: „Aus dem schattigen Wald ist er eben herausgetreten; in der Schwüle der Luft hat er den breitkrempigen Schlapphut vom Haupte gezogen, er macht im Gehen kurze Rast, sein treuer Gefährte, eine grosse Dogge, hat sich neben ihm niedergelassen." ${ }^{117}$ Wie Anzengruber auf dem Schmerlingplatz blickt auch der Leipziger Bismarck nach unten: auf einen Handwerker, der aber in anderer Weise als das Kunstwerk „Steinklopferhans“ zum Ruhm des im Denkmal Geehrten da ist. Der Schmiedemeister reicht dem „Schmied der deutschen Einheit einen Ehrenzweig (...) empor(...).“118

\section{Das Kunstwerk im Künstlerdenkmal und die Allegorie am Denkmal als Problem}

Das allegorische Verfahren, so wie es Walter Benjamin für das barocke Trauerspiel beschrieb, setzt voraus, dass das neu mit Sinn erfüllte Material und damit auch die Körper der Personifikationen - zunächst einmal entleert sein müssen, entwertet, tot. ${ }^{119} \mathrm{Im}$ Sinne Walter Benjamins definierte Aleida Assmann die Allegorie als Leerform. „Es ist wichtig zu betonen, dass der Signifikant der allegorischen Verkörperung, sein erborgtes Fleisch, keine Individualität, keine Geschichte hat. Er kennt kein Begehren

${ }^{118}$ Ibidem, Nr. 66.

${ }^{119}$ Dazu STEINHAGEN, H.: Zu Walter Benjamins Begriff der Allegorie - Symposion Wolfenbüttel 1978. In: Formen und Funktionen der Allegorie. Ed.: HAUG, W. (= Germanistische Symposien. Berichtsbände (...). Ed.: SCHÖNE, A., III). Stuttgart 1979, S. 666-685, hier S. 668 f. 
und keine Leiden, nicht einmal fiktive. ${ }^{، 120}$ Eben das sei einer der Gründe für die bevorzugte Nutzung des weiblichen Körpers als allegorisches Material, da dem die Auffassung von „Weiblichkeit als ,unmarkierte Form' des Menschseins" entspreche. ${ }^{121}$

Hat Anna Birkmeier am Grabmal Anzengrubers „keine Individualität, keine Geschichte“? Das hat sie anschaulich gewiss. Und das Leiden der Trauernden am Grabmal, in das sich unterdrücktes Begehren mischt, ist zwar die Trauer einer literarischen Gestalt, doch als solche glaubhaft, nicht weniger glaubhaft als in den Beispielen, in denen Gattinnen oder Töchter im Grabdenkmal ihre Trauer um den verstorbenen Gatten/Vater bekunden. Keineswegs ist hier die Bühnenfigur ein bloßes Bildzeichen für Trauer, und sie vertritt auch nicht nur zeichenhaft die Kunst Anzengrubers, sondern gewinnt leibhafte Wirklichkeit, Wirklichkeit, die präsenter und konkreter erscheint als das reliefierte Profilbildnis des Schöpfers dieser Kunstfigur. Aleida Assmann unterstrich allerdings auch, dass „,der allegorische Körper nicht in der Dienstbarkeit auf(geht)“. Anders als der geschriebene Begriff bringt der allegorische Körper seinen „Eigensinn“ ins Spiel. ${ }^{122}$ Der geht hier sehr weit: Im gegebenen Fall überspielt der „Eigensinn“ des Körpers die allegorische Spannung zwischen Signifikant und Signifikat. Anna Birkmeier ist aus ihrem Bühnenrahmen herausgetreten, hat Eigenleben gewonnen.

Alles andere als eine Leerform für abstrakte Botschaften ist auch der Steinklopferhans am Schmerlingplatz. Wie die Trauerfigur am Grabmal erdet ihn bereits seine Bodennähe. Anna Birkmeier, bzw. die „Verkörperung der Volkspoesie“, tritt vor dem Grabmal auf scheinbar natürliches Felsgestein, und auch der Steinklopferhans ist sockellos, es sei denn man wertete den Boden des fingierten Steinbruchs

\footnotetext{
120 ASSMANN, A.: Der Wissende und die Weisheit. In: Allegorien und Gescblechterdifferen₹: Eds.: SCHADE, S. - WAGNER, M. - WEIGEL, S. (= Literatur - Kultur - Geschlecht. Studien zur Literatur- und Kulturgeschichte. Eds.: STEPHAN, I. WEIGEL, S. Große Reihe, Bd. 3). Köln - Weimar - Wien 1994, S. 11-25, hier S. 12.

${ }^{121}$ ASSMANN 1994 (wie Anm. 120), S. 24.

${ }^{122}$ Ibidem, S. 12

${ }^{123}$ Vgl. REICHARDT 2009 (wie Anm. 95), S. 98.
}

als naturalistischen Sockel. ${ }^{123}$ Das markiert einen deutlichen Bruch mit der ästhetiktheoretischen Konvention, die den Sockel zur Bedingung der Möglichkeit der Erfahrung des Kunstwerks ansah. Die Begegnung des „Organischen“ (die Statue) mit dem „Unorganischen der Natur"، bedürfe, wie Lemckes „Populäre Ästhetik“ 1865 betonte, notwendig der Vermittlung. „Der steinerne Mensch, der wie ein lebendiger auf der Erde steht, wird widernatürlich erscheinen." "124 Vermittlungsarbeit und damit den Ausweis, dass das Kunstwerks ein Kunstwerk sei, leiste am ehesten architektonisch geordnetes Unorganisches, will heißen: ein Sockel. ${ }^{125}$ Der als Ästhetiktheoretiker prominentere Theodor Lipps argumentierte in diesem Sinne noch in seinen Publikationen aus dem ersten Jahrzehnt des 20. Jhs. Nur wenn die radikale „Isolation“ des Kunstwerks „Von dem, was sonst materielle Wirklichkeit hat", Isolation auch gegenüber anderen Kunstwerken, durch den Sockel in der Skulptur (analog: den Rahmen in der Malerei) „sichtbar" gemacht ist, gebe sich das Kunstwerk als das zu erkennen, was es ist: „eine Welt für sich“. ${ }^{126}$ Gegen dieses Gesetz werde oft verstoßen: „Vor allem sehen wir überall steinerne und bronzene Menschen und Tiere herumstehen, herumliegen und sich hinflegeln auf den Stufen der Sockel, im Wasser oder gar auf der bloßen Erde, die vom Künstler doch wohl eigentlich nicht als steinerne und bronzene Menschen oder Tiere in Stein oder Bronze gemeint sind." ${ }^{“ 127}$

Anna Birkmeier und der Steinklopferhanns stehen nicht herum und flegeln sich nicht hin, doch beide verzichten auf ein isolierendes Element. Und insofern sie Bodenhaftung in natürlicher Umgebung haben, ihnen also auch die Situation des Künstlerateliers und des Ausstellungsraums,

\footnotetext{
${ }^{124}$ LEMCKE, C.: Populäre Aesthetik. Leipzig 1865, S. 378.

${ }^{125}$ Grundlegend für die Forderung nach Aufsockelung von Statuen im öffentlichen Raum: HEGEL, G. W. F.: Vorlesungen über die Ästhetik II (= G. W. F. Hegel, Werke, Bd. 14). Frankfurt 1970, S. 353.

${ }^{126}$ LIPPS, TH.: Von der Form der ästhetischen Apperzeption (= Sonderdruck aus: Philosophische Abhandlungen. Dem Andenken Rudolf Hayms). Halle 1906, S. 111 f.

${ }^{127}$ LIPPS 1902 (wie Anm. 126), S. 406.
} 
die Rodins „Eva“ bei der sockellosen Präsentation ,rahmten', abgeht, tritt der von Lemcke und Lipps angeprangerte „,widernatürlich(e)“ Effekt ein. Sie erscheinen als lebendig gewordene Bronzen, bzw. als auf Dauer erstarrte lebende Bilder, und sie konnten wie diese „peinlich“ wirken, weil sie „allzu lange in

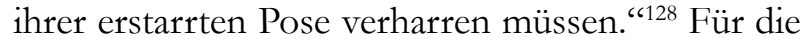
klassische Moderne war damit der Urteilsspruch gesprochen. Doch die klassische Moderne ist selbst bereits historisch geworden. Ihr Werteprofil gehört auf den Prüfstand, und Ergebnis der Prüfung könnte sein, dass Objekte, wie die in diesem Beitrag behandelten, einen Rang beanspruchen dürfen, der sich in der Aufmerksamkeit, die die Forschung dem Werk Hans Scherpes bislang schenkte, nicht zureichend abbildet.

Sollte man diese ,erstarrten lebende Bilder' überhaupt unter den Begriff der Allegorie stellen? Mit den vollplastischen Personifikationen an Begas' Berliner Schillerdenkmal war die Zuordnung zur Allegorie bereits, wie gesehen, in Frage gestellt worden. Die zu Einzelwerken oder zu Figuren aus Einzelwerken des Künstlers verdichteten Personifikationen konnten als noch weiter entfernt von dem wahrgenommen werden, was man mit der herkömmlichen Allegorie verband: Allgemeinheit, Begrifflichkeit, Kälte. Jacob Burckhardt rechnete in einem Vortrag des Jahres 1887 die literarischen Gestalten, die an Dichtergrabmälern den Geehrten beigegeben sind - er bezog sich auf Ludwig von Schwanthalers Frankfurter Goethe-Denkmal - nicht zu den Allegorien. ${ }^{129}$ Man wird Burckhardt entgegenhalten, dass bei Schwanthaler zunächst die im Relief dargestellten Bühnen- Roman- und Gedichtfiguren sich den Bildraum mit eindeutigen Allegorien teilen (Viktoria, sowie den Personifikationen von Wissenschaft, Drama und Lyrik), aber auch, dass die Bühnenfiguren nicht nur für sich, sondern stellvertretend für allgemeinere Aspekte des goetheschen

\footnotetext{
${ }^{128}$ SCHUMACHER, F.: Denkmalkunst. In: Der Kunstwart, 15, 1902, Heft 11, S. 509-519, hier S. 517. Vgl. TRAGATSCHNIG 2004 (wie Anm. 79), S. 226.

${ }^{129}$ BURCKHARDT, J.: Die Allegorie in den Künsten (1887). In: BURCKHARDT, J., Vorträge (= Jacob Burckhardt-Gesamtausgabe, 14. Bd.). Stuttgart - Berlin - Leipzig 1933, S. 419-438, hier S. 422.
}

Werks stehen. So verkörpern beispielsweise auf dem rückseitigen Relief Erlkönig, Prometheus und der Perser die Lyrik, und besondern sich zudem in die auf deutsche, antike und orientalische Themen bezogenen lyrischen Dichtungen Goethes. ${ }^{130}$ Insofern steht das Personal aus Goethes Werken nicht allein anschaulich auf einer Ebene mit Personifikationen, sie personifizieren selber. Doch bleibt etwa beim Erlkönig der Verweis auf das Allgemeine, hier die Lyrik, beiläufiger als auf der Sockelvorderseite der Verweis der als Personifikation offensichtlichen Sitzfigur mit der Lyra und dem Füllhorn zu Füßen auf die lyrische Dichtkunst. Insofern als Burckhardt in seinem „Allegorie-Vortrag“ das „Abstractum“ gleichbedeutend mit ,allegorischer Figur" gebrauchte, ${ }^{131}$ mussten ihm notwendig der Erlkönig, Iphigenie, Wilhelm und die anderen bestimmter, wirklicher, erscheinen.

Einige Jahre vor Burckhardt Allegorie-Vortrag publizierte der Altphilologe und Archäologe Hugo Blümner das Erste Heft seiner „Laokoon-Studien“, das dem „Gebrauch der Allegorie in den bildenden Künsten" gewidmet war. Blümner lehnte allegorische Figuren ab, soweit ihr Wirklichkeitsanspruch nicht, wie im antiken Griechenland, auf einem religiöses Fundament bauen konnte. Konzessionen gestand er zu, da das Kunstleben seiner Zeit in der Praxis oft keine andere Wahl lasse. ${ }^{132}$ So weit als möglich sollte aber gerade in der Gattung der Skulptur, von der als in der Regel öffentliche Kunstgattung im besonderen Maße Verständlichkeit erwartet werde, nach Alternativen gesucht werden. Für Kriegerdenkmäler empfahl er konkrete Szenen aus dem Krieg an die Stelle von Allegorien der Tapferkeit, der Vaterlandsliebe usw. zu setzen. Analog seine Empfehlung an die Bildhauer, die mit Künstlerdenkmälern befasst seien: Statt die poetischen Gattungen - Epos, Lyrik, Tragödie usw. - in denen der Geehrte geglänzt habe, zu allegorisieren, sollten „Hauptgestalten aus seinen Werken (und wenn es sich um Reliefs handelt, Scenen daraus)“

${ }^{130}$ APPELL, J. W.: Das Haus mit den drei Lyren und das Goethedenkmal in Frankfurt a. M. Frankfurt 1849, S. 18.

131 BURCKHARDT 1933 (wie Anm. 129), S. 419. Zu Burckhardts Allegoriebegriff: Trabatschnig 2004 (wie Anm. 79), S. 214.

132 BLÜMNER 1881 (wie Anm. 113), S. 90 f. 
am Sockel auftreten. ${ }^{133}$ Blümner war sich im Klaren darüber, dass das nicht in jedem Fall problemfrei realisiert werden könne. Wohingegen „Hauptgestalten“ aus Werken eines Opernkomponisten sich unkompliziert anböten, ließen sich die Personikationen von Volkslied oder Symphonie nicht so leicht ersetzen. Mit Zumbuschs „Prometheus“ am Sockel des Wiener Beethoven-Denkmals, der sowohl für das titanische Ringen und die persönliche Tragik Beethovens stehe, als auch auf ein Werk Beethovens verweise, wusste er immerhin ein geglücktes Beispiel. ${ }^{134}$

1902 sprach sich auch Ernst Schultze in seiner Schrift „Wie wir unsere großen Dichter ehren sollten. Ein Wort über Dichter-Denkmäler und andere" gegen unverständlich gewordene Allegorien am Denkmal aus. Er empfahl stattdessen „Figuren aus den Hauptwerken der Dichter dar(zu)stellen.“ Allerdings lehnte er „Figuren, die körperlich heraustreten" ab und schlug das Medium des Reliefs für die Ikonographie des Kunstwerks am Denkmal vor, um der Gefahr zu entgehen, unter dem im Denkmal Geehrten ,ein versteinerte(s) Ballett" zu inszenieren. ${ }^{135}$ Dem Grabdenkmal Anzengrubers konzedierte er immerhin „einen hohen Stimmungswert". Er nannte allerdings nur das Porträt des Literaten; die Trauerfigur verschwieg er. ${ }^{136}$ Kunstfiguren im Relief, halten eben eher - im Wortsinne - den Rand, entfalten ihre Aktivität eher (mit dem singenden Homer am Grabmal für Philippe-Laurent Roland hatte wir eine Ausnahme gesehen) innerhalb des Rahmens. Wie der Steinklopferhans beansprucht Anna Birkmeier ein Realitätsniveau, das tatsächlich, wovor Schultze warnte, die Aufmerksamkeit vom Betrauerten abziehen konnte. ${ }^{137}$ Sie ziehen Aufmerksamkeit ab, weil sie als Beifiguren am Denkmal / Grabmal sich soweit freigesetzt / konkretisiert haben, dass sie ein Eigenleben führen und nicht länger allegorisch dienstbar bleiben. Das vier Jahre nach Scherpes Anzengruber-Denkmal und sechzehn Jahre nach Scherpes Anzengruber-Grabmal fertiggestellte Grabmal für den Maler Jean-Baptiste Greuze wurde eingangs als beunruhigend bis unheimlich beschrieben. Und bereits James Pradiers „Sappho“ in seinem von Étex projektierten Grabmal hätte sich zu einer „Pleureuse“ emanzipiert, hätte sich freigesetzt auch und gerade von den Intentionen, die ihr Schöpfer in sie gelegt hatte. Die literarischen Figuren in Hans Scherpes Grabdenkmal und Denkmal für Ludwig Anzengruber sind ebenfalls und beunruhigend frei geworden. Sie werden in neuer, vom Text unabhängiger Weise, aktiv, weil sie aus dem Rahmen treten und in einen neuen Rahmen eintreten.

\footnotetext{
${ }^{133}$ Ibidem, S. 75 f.

${ }^{134}$ Ibidem, S. 77.

${ }^{135}$ SCHULTZE, E.: Wie wir unsere großen Dichter ehren sollten. Ein Wort über Dichter-Denkmäler und andere. Leipzig 1902, S. 9.
}

${ }^{136}$ Ibidem, S. 12.

${ }^{137}$ Ibidem, S. 9. 


\title{
The Artwork Mourns - the Artwork Praises. Ludwig Anzengruber's Tomb and Monument in Vienna in the European Context
}

\begin{abstract}
Résumé
At Michelangelo's tomb in S. Croce, Florence (previously on his catafalque), personifications of the arts appear for the first time to honour an artist, and with the statuette holding the personification of the "Pittura" (formerly the "Scultura") in its hands, the allusion to an artwork by the deceased artist is also explicitly present at the tomb for the first time. Initially only attribute of a personification, in the 19th century the work of art can rise to an independently acting figure, who alongside or instead of personifications, geniuses, muses mourns its creator in the tomb or praises him in the monument.

A young countrywoman, who generally stands for the popular work of Ludwig Anzengruber, but also means a concrete stage figure, laments

the deceased poet at the tomb in Vienna's Central Cemetery. In the monument to Ludwig Anzengruber on Vienna's Schmerlingplatz, the statue of Anzengruber encounters the "Steinklopferhans", perhaps Anzengruber's most popular stage figure. In both works - in the tomb as well as in the monument - the literary figures step out of their "frames" (Anzengruber's plays), unfolding their own life and activity independent of their literary context. The Anzengruber Tomb and the Anzengruber Monument are works by Hans Scherpe, who has received little attention in art historical literature. In the present contribution, the innovative aspects of these works will be examined and placed in the context of European memorial culture.
\end{abstract}

